San Jose State University

SJSU ScholarWorks

Mineta Transportation Institute Publications

$6-2020$

Development of Reduced Chemical Kinetic Models for the

Numerical Simulation of Combustion and Emissions Behavior of

Representative Conventional and Bio-derived Fuels

Mazen A. Eldeeb

California State University, Fresno

Follow this and additional works at: https://scholarworks.sjsu.edu/mti_publications

Part of the Biology and Biomimetic Materials Commons, and the Heat Transfer, Combustion Commons

Recommended Citation

Mazen A. Eldeeb. "Development of Reduced Chemical Kinetic Models for the Numerical Simulation of Combustion and Emissions Behavior of Representative Conventional and Bio-derived Fuels" Mineta Transportation Institute Publications (2020). https://doi.org/10.31979/mti.2020.1910

This Report is brought to you for free and open access by SJSU ScholarWorks. It has been accepted for inclusion in Mineta Transportation Institute Publications by an authorized administrator of SJSU ScholarWorks. For more information, please contact scholarworks@sjsu.edu. 


\section{SJSU SAN OSE STATE \\ MTI/ Mans}

Development of Reduced Chemical Kinetic Models for the Numerical Simulation of Combustion and Emissions Behavior of Representative Conventional and Bio-Derived Fuels

Mazen A. Eldeeb, PhD

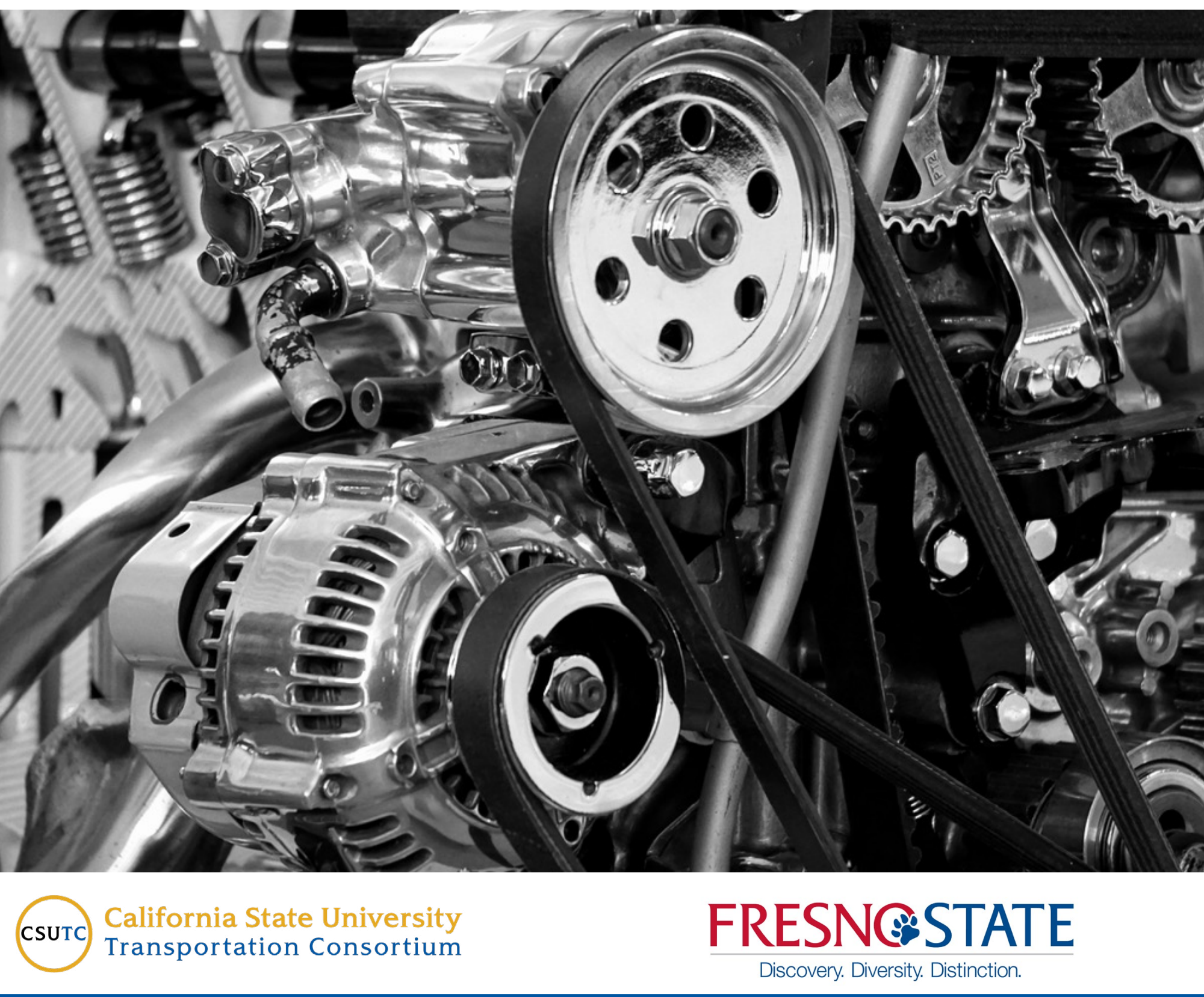




\section{MINETA TRANSPORTATION INSTITUTE}

Founded in 199I, the Mineta Transportation Institute (MTI), an organized research and training unit in partnership with the Lucas College and Graduate School of Business at San José State University (SJSU), increases mobility for all by improving the safety, efficiency, accessibility, and convenience of our nation's transportation system. Through research, education, workforce development, and technology transfer, we help create a connected world. MTI leads the four-university. MTI leads the four-university California State University Transportation Consortium funded by the State of California through Senate Bill I.

MTl's transportation policy work is centered on three primary responsibilities:

\section{Research}

MTI works to provide policy-oriented research for all levels of government and the private sector to foster the development of optimum surface transportation systems. Research areas include: bicycle and pedestrian issues; financing public and private sector transportation improvements; intermodal connectivity and integration; safety and security of transportation systems; sustainability of transportation systems; transportation / land use / environment; and transportation planning and policy development. Certified Research Associates conduct the research. Certification requires an advanced degree, generally a Ph.D., a record of academic publications, and professional references. Research projects culminate in a peer-reviewed publication, available on TransWeb, the MTI website (http://transweb.sjsu.edu).

\section{Education}

The Institute supports education programs for students seeking a career in the development and operation of surface transportation systems. MTI, through San José State University, offers an AACSBaccredited Master of Science in Transportation Management and graduate certificates in Transportation Management, Transportation Security, and High-Speed Rail Management that serve to prepare the nation's transportation managers for the 2 I st century. With the active assistance of the California Department ofTransportation (Caltrans), MTI delivers its classes over a state-of-the-art videoconference network throughout the state of California and via webcasting beyond, allowing working transportation professionals to pursue an advanced degree regardless of their location. To meet the needs of employers seeking a diverse workforce, MTl's education program promotes enrollment to under-represented groups.

\section{Information and Technology Transfer}

MTI utilizes a diverse array of dissemination methods and media to ensure research results reach those responsible for managing change. These methods include publication, seminars, workshops, websites, social media, webinars, and other technology transfer mechanisms. Additionally, MTI promotes the availability of completed research to professional organizations and journals and works to integrate the research findings into the graduate education program. MTl's extensive collection of transportation- related publications is integrated into San José State University's world-class Martin Luther King, Jr. Library.

\section{Disclaimer}

The contents of this report reflect the views of the authors, who are responsible for the facts and accuracy of the information presented herein. This document is disseminated in the interest of information exchange. The report is funded, partially or entirely, by a grant from the State of California. This report does not necessarily reflect the official views or policies of the State of California or the Mineta Transportation Institute, who assume no liability for the contents or use thereof. This report does not constitute a standard specification, design standard, or regulation. 
REPORT 20-12

\title{
DEVELOPMENT OF REDUCED CHEMICAL KINETIC MODELS \\ FOR THE NUMERICAL SIMULATION OF COMBUSTION AND EMISSIONS BEHAVIOR OF REPRESENTATIVE CONVENTIONAL AND BIO-DERIVED FUELS
}

\author{
Mazen A. Eldeeb
}

June 2020

A publication of

Mineta Transportation Institute

Created by Congress in 1991

College of Business

San José State University

San José, CA 95192-0219 


\section{TECHNICAL REPORT DOCUMENTATION PAGE}

1. Report No. 20-12

4. Title and Subtitle

Development of Reduced Chemical Kinetic Models for the Numerical Simulation of Combustion and Emissions Behavior of Representative Conventional and Bio-derived Fuels

2. Government Accession No.
7. Authors

Mazen A. Eldeeb

9. Performing Organization Name and Address

Mineta Transportation Institute

College of Business

San José State University

San José, CA 95192-0219

12. Sponsoring Agency Name and Address

State of California SB1 2017/2018

Trustees of the California State

University

Sponsored Programs Administration

401 Golden Shore, 5th Floor

Long Beach, CA 90802
3. Recipient's Catalog No.

5. Report Date

June 2020

6. Performing Organization Code

8. Performing Organization Report CA-MTI-1910

\section{Work Unit No.}

11. Contract or Grant No. ZSB12017-SJAUX

13. Type of Report and Period Covered Final Report

14. Sponsoring Agency Code

15. Supplemental Notes

DOI: $10.31979 / \mathrm{mti} .2020 .1910$

\section{Abstract}

The study addresses two of the main challenges facing combustion modeling for transportation fuels: simultaneous simulation of non-related combustion problems and reducing the computational cost of the modeling process itself. To address the first challenge, researchers determine a characteristic flame time from thermal diffusivity and laminar burning velocity. Researchers examine parametric dependence of flame time and ignition delay time on pressure, temperature and equivalence ratio for methane, based on validated chemical kinetic mechanisms. The study reveals flame time and ignition delay time show similar temperature dependence, flame time has stronger dependence on equivalence ratio and weaker dependence on pressure than ignition delay time. The study also establishes a correlation to predict flame time, and subsequently, burning velocity, based on knowledge of the relevant auto ignition time. Differences between methane, propane and ethanol are also explored.

Researchers address the second challenge in a chemical kinetic modeling study of the high-temperature ignition behavior of Tetrahydrofuran (THF), a promising second-generation transportation biofuel. The study implements a Stochastic Species Elimination (SSE) reduction approach to develop multiple skeletal versions of a detailed chemical kinetic model of THF from the literature based on ignition delay time simulations at various pressures and temperatures. The developed skeletal versions are combined into a global skeletal model. The study uses ignition delay time simulations using detailed and skeletal models, with good agreement observed at higher temperatures. Next, researchers use sensitivity analysis to identify the most important reactions responsible for the performance of the skeletal model. Finally, they perform reaction rate parameter modification for such reactions in order to improve the agreement of detailed and reduced model predictions with literature experimental ignition data.

This work contributes toward improved understanding and modeling of the oxidation kinetics of conventional and bio-derived transportation biofuels, as well as the estimation of laminar burning velocity that can be encountered in turbulent combustion simulations. This would ultimately contribute into the design of cleaner and more efficient transportation systems, and support the testing and adoption of novel fuels as additives and/or replacement to conventional non-renewable fossil fuels.

\section{Key Words}

Motor fuels, biomass fuels, combustion, simulation
18. Distribution Statement

No restrictions. This document is available to the public through The National Technical Information Service, Springfield, VA 22161
19. Security Classif. (of this report) Unclassified
20. Security Classif. (of this page)

Unclassified
21. No. of Pages

35
22. Price 


\section{Copyright $\odot 2020$ \\ by Mineta Transportation Institute \\ All rights reserved}

DOI:
10.31979/mti.2020.1910

$10.31979 / \mathrm{mt} .2020 .1910$

Mineta Transportation Institute
College of Business

San José State University

San José, CA 95192-0219

Tel: (408) 924-7560

Fax: (408) 924-7565

Email: mineta-institute@sjsu.edu

transweb.sjsu.edu 


\section{ACKNOWLEDGMENTS}

Support from Fresno State Transportation Institute (FSTI) and Lyles College of Engineering at Fresno State is acknowledged. The authors thank Editing Press, for editorial services, as well as MTI staff, including Executive Director Karen Philbrick, PhD; Deputy Executive

Director Hilary Nixon, PhD; Graphic Designer Alverina Eka Weinardy; and Executive Administrative Assistant Jill Carter. 


\section{TABLE OF CONTENTS}

$\begin{array}{lr}\text { Executive Summary } & 1\end{array}$

I. Introduction and Motivation 3

II. Parametric Dependence of Flame Time 6

$\begin{array}{ll}\text { Methodology } & 6\end{array}$

Results $\quad 8$

$\begin{array}{ll}\text { Discussion } & 12\end{array}$

III. THF Model Reduction and Analysis 14

$\begin{array}{ll}\text { Methodology } & 14\end{array}$

Results 15

$\begin{array}{ll}\text { Discussion } & 21\end{array}$

$\begin{array}{ll}\text { IV. Conclusion and Future Research } & 23\end{array}$

$\begin{array}{ll}\text { Abbreviations and Acronyms } & 26\end{array}$

$\begin{array}{lr}\text { Endnotes } & 27\end{array}$

$\begin{array}{ll}\text { Bibliography } & 31\end{array}$

$\begin{array}{lr}\text { About the Author } & 34\end{array}$

$\begin{array}{ll}\text { Peer Review } & 35\end{array}$ 


\section{LIST OF FIGURES}

1. Flame Time and Ignition Delay Time Variation with Critical Temperature for Methane/Air Mixtures (at pressures of 1.0 and 20 bars and equivalence ratios of 0.75 and 1.25 )

2. Flame Time Pressure Dependence of Methane/Air Mixtures at Pressures of 1.0-20 Bars and Equivalence Ratios of 0.75 and 1.25

3. Ignition Delay Time Pressure Dependence of Methane/Air Mixtures at Pressures of 1.0-20 Bars and Equivalence Ratios of 0.75 and 1.25

4. Flame Times versus Ignition Delay Times for Methane/Air Mixtures at Pressures of 1.0-20 Bar and Equivalence Ratios of 0.6-1.6

5. Flame Times of Methane, Propane, and Ethanol Mixtures with Air at Pressures of 1.0 and 10 Bars and Equivalence Ratios of 0.75 and 1.0

6. Comparison of Ignition Delay Simulations using the Global Skeletal and Original THF Detailed Models with Shock Tube data for Stoichiometric THF/Air Mixtures at Pressures of 6.4 and 9.1 Bar

7. Brute-force Reaction Sensitivity Analysis using Detailed and Global Skeletal Versions for Stoichiometric THF/Air Mixture at 9.1 Bar and $1000 \mathrm{~K}$

8. Brute-force Reaction Sensitivity Analysis using Skeletal Model for Stoichiometric THF/Air Mixture at 9.1 Bar and Temperatures of 700, 1000 , and $1300 \mathrm{~K}$

9. Predictions of Modified Skeletal Model with Unmodified Skeletal Model (original THF detailed model and shock tube measurements by Fenard et al. for stoichiometric THF/air mixtures at pressures of 6.4 and 9.1 bar) 


\section{LIST OF TABLES}

1. Updated Reaction Rate Parameters Applied to the Skeletal THF Model (Reactions as shown in model). 


\section{EXECUTIVE SUMMARY}

The development of chemical kinetic models has become a main area of combustion research, necessitated by the fact that these models describe the chemical kinetics of combustion processes more accurately than global reaction models. Developing chemical kinetic models has attracted increased research activity in measuring key combustion properties, such as ignition delay times and laminar burning velocity, mechanistic exploration of new reaction pathways, and evaluation of the propensity of biofuels to emit pollutants such as $\mathrm{CO}, \mathrm{NO}_{\mathrm{x}^{\prime}}$, $\mathrm{SO}_{x}$, soot, and particulate matter. Modeling efforts are further prompted by the need for combustion models of emerging fuels such as biofuels. ${ }^{1}$

Fuel-flexible combustion technology is advanced through validated kinetic models, which can be used for computer-aided development of novel combustion engines, ultimately aimed at the development of clean and efficient transportation systems. Numerical modeling is one of the most powerful tools used for that purpose, as it provides flexibility and low cost compared to experimental characterization. The synergy between chemical kinetic mechanisms and three-dimensional computational fluid dynamics (3D-CFD) flow simulations is necessary for the simulation of combustion and emissions behavior of second-generation biofuels as well as their blends with conventional fuels in existing compression ignition $(\mathrm{Cl})$, spark ignition (SI), dual-fuel and homogeneous charge compression ignition $(\mathrm{HCCl})$ engines.

However, the use of chemical kinetic models for combustion and emission simulations requires efforts to overcome two main challenges. The first challenge is that simulating main combustion properties such as ignition delay time and laminar burning velocity require different types of numerical models, as these are two separate combustion problems that occur at different settings. Simultaneous simulations of such properties require exploring a potential link. Such a link can particularly facilitate estimation of the flame propagation behavior of fuels from knowledge of their auto-ignition behavior, which are two separate combustion problems.

The second challenge is reducing the computational cost, as the use of the resulting chemical kinetic models in computational combustion analysis is limited by their large sizes. Chemical kinetic models often contain tens of thousands of reactions among hundreds or thousands of species. Coupling these to the turbulent flows characteristic of combustion is therefore challenging. One approach to decrease the computational cost of detailed models is to reduce them to smaller sizes while retaining prediction capabilities of practical interest. ${ }^{2}$ The motivation behind the sustained search for methods of mechanism reduction is to enable researchers in the combustion field to conveniently obtain reduced models efficiently without necessarily acquiring skills in chemical kinetic modeling. While most existing methods do not require detailed chemical kinetic insight, the methods tend to require substantial programming, judging from the few research groups using the proposed methods.

This work provides an attempt to address these two challenges. To address the challenge of linking auto-ignition and flame propagation simulations, a characteristic flame time, defined in the thermal flame theory, is determined from thermal diffusivity and laminar burning velocity. Parametric dependence of flame time and ignition delay time on pressure, temperature and equivalence ratio is examined based on validated chemical kinetic mechanisms for 
methane, propane, and ethanol. This is done to explore similarities and differences between the two characteristic times and their dependence on combustion conditions, and eventually to developing a correlation between flame time and ignition delay time. Such a correlation enables the prediction of laminar burning velocity of a given fuel under a specific condition based on ignition delay time knowledge, and it therefore enables simultaneous simulation of both properties.

The second challenge is addressed in a chemical kinetic modeling study of the hightemperature ignition behavior of Tetrahydrofuran (THF), a promising second-generation transportation biofuel. THF was chosen as the fuel of interest to represent second-generation biofuels, an environmentally friendly alternative to fossil fuels and one which can replace them without major engine modifications. Such biofuels have a great potential for production from sugars and biomass, ${ }^{3}$ unlike alcohols that are mostly manufactured from edible sources such as corn. These properties promote second-generation biofuels as alternative fuels, especially in the transportation sector, which accounts for $21 \%$ of global energy consumption. ${ }^{4}$ The Stochastic Species Elimination (SSE) reduction approach is implemented to develop multiple skeletal versions of a chemical kinetic model of THF based on ignition delay time simulations at various pressures and temperatures as detailed in the literature. The developed skeletal versions are combined into a global skeletal model. Ignition delay times are simulated using detailed and skeletal models, with good agreement observed at higher temperatures. Sensitivity analysis is then performed to identify the most important reactions responsible for the performance of the skeletal model. Reaction rate parameter modification is performed for such reactions in order to improve the agreement of detailed and reduced model predictions with experimental ignition data from the literature.

The proper chemical kinetic modeling of the combustion and emission behavior of secondgeneration biofuels would identify potentially favorable characteristics of such fuels relative to conventional fossil fuels used in the transportation sector, both qualitatively and quantitatively. This work contributes toward improved understanding and modeling of the oxidation kinetics of conventional and bio-derived transportation biofuels, as well as the estimation of laminar burning velocity that can be encountered in turbulent combustion simulations. This in turn would be a helpful effort towards reducing the impact of the transportation sector on the environment and climate change, which is one of the main objectives of California's cap-andtrade program (SB-1 Objective 5). The findings of such modeling effort would provide invaluable information that can support and improve the decision-making processes surrounding transportation-related issues. For instance, the results of this project can provide valuable information to the governmental agencies in California, such as the California Air Resources Board, with respect to the estimated emission levels of furans combustion. Additionally, the results of this project can promote the mass-production of furans from biomass, which can be helpful to the farming businesses in the Central Valley and beyond, as agricultural waste is a main feedstock for cellulose, necessary for the production of furans. 


\section{INTRODUCTION AND MOTIVATION}

The development of detailed and reduced chemical kinetic models has become a main area of combustion research. Compared with global reaction models, such models can reasonably describe the chemical kinetics of the combustion processes. Increased research activity is currently focused on chemical kinetic model development through the experimental investigation of fundamental combustion properties, such as ignition delay times and laminar burning velocity, mechanistic exploration of new reaction pathways, and evaluation of the emission propensity of biofuels for pollutants such as $\mathrm{CO}, \mathrm{NO}_{x}, \mathrm{SO}_{x}$, soot, and particulate matter. The emergence of fuels such as second-generation biofuels, which have the potential to be used for the transportation industry, prompt further modeling efforts to enable the simulation of combustion events of such fuels. ${ }^{5}$

Second-generation biofuels, such as tetrahydrofuran (THF), are an environmentally friendly alternative to fossil fuels and can substitute them without major engine modifications. Moreover, they have significantly lower greenhouse gas emissions than fossil fuels, because of $\mathrm{CO}_{2}$ recycling through agricultural activities. ${ }^{6}$ In addition, they have superior energy densities, engine knock resistance, and Research Octane Numbers (RON) to first-generation biofuels, such as bio-alcohols, ${ }^{7}$ making them promising spark ignition (SI) engine fuels. Also, they have a great potential for production from sugars and biomass, ${ }^{8}$ unlike alcohols that are mostly manufactured from edible sources such as corn. These properties promote second-generation biofuels as alternative fuels, especially in the transportation sector, which accounts for $21 \%$ of global energy consumption. ${ }^{9}$

Validated chemical kinetic models contribute to the advancement of fuel-flexible combustion technology, since they can be used for computer-aided development of novel combustion engines, ultimately leading to the development of cleaner and more efficient transportation systems. Numerical simulation is a powerful tool that can be used for that purpose. Compared to experimental characterization, numerical modeling is more flexible and less expensive. The synergy between chemical kinetics mechanisms and three-dimensional computational fluid dynamics (3D-CFD) flow simulations is necessary for the simulation of the combustion and emissions behavior of second-generation biofuels as well as their blends with conventional fuels in existing compression ignition $(\mathrm{Cl})$, spark ignition (SI), dual-fuel and homogeneous charge compression ignition $(\mathrm{HCCl})$ engines.

The estimation of laminar burning velocity of premixed flames is also one of the most commonly encountered combustion problems, since laminar burning velocity is an important means of combustion characterization. Turbulent combustion simulations can be supported by this estimation, which serves as a front-tracking method to approach the more complicated turbulent combustion problem. Laminar flame front can be used in this case as computational degrees of freedom. The purpose of this approach is eliminating the possibility of discontinuities in the thermal state, concentration, or thermodynamic phase that can result from the application of Eulerian advection methods. ${ }^{10}$

However, two main challenges to the development and use of chemical kinetic models are present. The first challenge is the fact that various reactor models are needed for the modeling and simulation of different combustion problems. For example, the simulation of flame 
propagation behavior and auto-ignition behavior are fundamentally two separate combustion problems that take place in different reactor types. In addition, the mass transport properties of involved species are crucial for flame speed simulations, in addition to the thermodynamic properties and reaction rate constants that are necessary for estimating ignition delay time.

The thermal flame theory ${ }^{11}$ provides mathematical descriptions of the propagation of stationary one-dimensional premixed flames. The results of this theory enable the characterization of flame propagation using the time during which the flame front travels by a single flame thickness, referred to as the flame time. According to the thermal flame theory, flame time is a function of the mixture's thermal diffusivity and the laminar burning velocity. As a result, some level of similarity can be established between the flame propagation problem and the auto-ignition problem, as both problems can be characterized by a time scale.

Therefore, it is necessary to explore the dependence of flame time on combustion process parameters such as temperature, pressure, and mixture composition. The two determinants of flame time, thermal diffusivity and laminar burning velocity, are both temperature- and pressure-dependent. By establishing comparative parametric dependence profiles of flame time and ignition delay time on such parameters, a correlation can be developed to link both characteristic times, which ultimately results in the possible prediction of flame times, and subsequently laminar burning velocity, from ignition delay time at a specific condition. The development of such correlations can enable researchers to design a machine learning process to estimate laminar burning velocity from ignition delay time and adiabatic flame temperature.

Another challenge to chemical kinetic modeling of combustion events is that the use of the chemical kinetic models in computational combustion simulations is limited by their large sizes, which necessitates efforts for computational cost reduction. Chemical kinetic models typically contain thousands of reactions between hundreds or thousands of species, which means a huge number of ordinary differential equations to solve simultaneously. Coupling these with the already complex and turbulent nature of combustion is even more challenging. Model reduction is an approach that is used to decrease the computational cost of detailed models by reducing them to smaller sizes while retaining predictive performance of interest. ${ }^{12}$ Sustained search efforts to develop methods of mechanism reduction aim at providing combustion researchers with convenient ways to reduce models efficiently with little to no expert knowledge in chemical kinetics, such as the Directed Relations Graph (DRG) method, ${ }^{13}$ in which the important species are identified by their direct effect on the concentration of a target species, most commonly the fuel. Other methods include DRG with error propagation analysis (DRGEP) ${ }^{14}$ and species sensitivity analysis (DRGASA), ${ }^{15}$ DRG with expert knowledge (DRGX), ${ }^{16}$ as well as the sensitivity-based Stochastic Species Elimination (SSE) approach, ${ }^{17}$ which was recently developed, validated, and used to produce reduced versions of detailed models of $n$-heptane, iso-octane and $n$-octanol. 18 However, even in the case of existing reduction methods that do not require detailed chemical kinetic insight, substantial programming skills are often required.

This work is an attempt to address the aforementioned challenges to chemical kinetic modeling. To address the first challenge, a novel exploratory approach is implemented through the calculation of flame times for methane, propane, and ethanol at various pressure, 
temperature, and equivalence ratio conditions. The first two fuels are representatives for linear alkanes used as transportation fuels, while the third is a representative alcohol-based transportation biofuel. The comparative dependence profiles of flame time and ignition delay time on such parameters are explored. A correlation for flame time estimation from ignition delay time is developed and analyzed.

In addition, the second challenge is addressed in a chemical kinetic modeling study of the high-temperature ignition behavior of Tetrahydrofuran (THF). Stochastic Species Elimination (SSE) reduction approach is used to develop multiple reduced versions of a detailed chemical kinetic model of THF from the literature, based on ignition delay time simulations at various pressures and temperature conditions. The developed reduced versions are combined into an overall skeletal model. Ignition delay time simulations are performed using detailed and skeletal models. Sensitivity analysis is performed to identify the most important reactions responsible for the performance of the skeletal model. Reaction rate parameters are modified for such reactions in order to improve the predictive performance of detailed and reduced models compared with experimental ignition data from the literature.

The findings of this work should be of interest to agencies and businesses interested in testing the combustion and emission behavior of potential transportation fuels, such as governmental environment protection agencies, the oil and petrochemical industry, and automotive companies. Knowledge of combustion principles and chemical kinetics would aid the full comprehension of this report. 


\section{PARAMETRIC DEPENDENCE OF FLAME TIME}

\section{METHODOLOGY}

Flame propagation can be characterized by flame time in seconds, which is defined in the thermal flame theory as the time a flame takes to propagate by one flame thickness, and it can be calculated as follows:

$$
\tau_{f}=\frac{\alpha}{S_{L}{ }^{2}}
$$

where $\alpha$ is the thermal diffusivity in $\mathrm{m}^{2} / \mathrm{s}$ and $S_{L}$ is the laminar burning velocity in $\mathrm{m} / \mathrm{s}$. The thermal diffusivity can be calculated from mixture properties as follows:

$$
\alpha=\frac{k}{\rho c_{p}}
$$

where $k$ is the mixture's thermal conductivity in $\mathrm{W} / \mathrm{m} \cdot \mathrm{K}, \rho$ is the mass density in $\mathrm{kg} / \mathrm{m}^{3}$, and $c_{p}$ is the constant-pressure specific heat in $\mathrm{J} / \mathrm{kg} \cdot \mathrm{K}$.

The above equations show that the estimation of laminar burning velocity is crucial for flame time calculation. For that purpose, laminar burning velocity simulations are carried out in CHEMKIN-PRO software package using the PREMIX solver for laminar 1-D premixed flames. ${ }^{19}$ Although simulations that use the PREMIX solver do not output a mixture's thermal diffusivity directly, it is calculated according to equation by averaging the readily available thermal conductivity, density, and specific heat values all over the grid.

This part of the study is aimed at establishing a comparative parametric analysis of flame time with another combustion property of the same nature used to characterize a different combustion problem, such as auto-ignition delay time $\left(\tau_{i}\right)$. For this purpose, ignition delay time simulations are also performed using CHEMKIN-PRO's constant-pressure closed homogeneous batch reactor and SENKIN solver. ${ }^{20}$ The temperature chosen for performing such simulations is the average of the unburnt and adiabatic flame temperatures, referred to as the critical temperature $\left(T_{c r}\right)$, such that:

$$
T_{c r}=\frac{T_{u}+T_{a d}}{2}
$$

where $T_{u}$ is the unburnt flame temperature and $T_{a d}$ is the adiabatic flame temperature, both in Kelvin. CHEMKIN-PRO's chemical and phase equilibrium reactor model and the EQUIL solver ${ }^{21}$ are used for adiabatic flame temperature simulations.

Methane $\left(\mathrm{CH}_{4}\right)$ is chosen as the target fuel for flame time parametric dependence investigation to represent simple linear alkanes that are utilized as transportation fuels. As a result, flame speed, ignition delay time, and adiabatic flame temperature simulations are performed for methane in CHEMKIN-PRO using a chemical kinetic model of methane and propane by Petersen et al. ${ }^{22}$ Since this model lacks transport properties necessary 
for laminar burning velocity simulations, this work couples the aforementioned model with the primary reference fuel (PRF) transport properties from the iso-octane model by Mehl et al. ${ }^{23}$ in flame speed simulations.

Laminar burning velocity simulations for $\mathrm{CH}_{4}$ are performed first at pressures $(p)$ of 1-20 bars, unburnt gas temperatures of 300-1000 K, equivalence ratios $(\phi)$ of $0.6-1.6$, and a dilution ratio $(D)$ of 3.76 which represents the $\mathrm{N}_{2} / \mathrm{O}_{2}$ ratio in the mixture. Also, ignition delay time simulations are performed at the same conditions of pressure and equivalence ratio, and at critical temperatures calculated as shown in equation. Adiabatic flame temperatures are calculated in CHEMKIN-PRO's equilibrium model at the abovementioned pressures and equivalence ratios. The variation of both ignition delay times and flame times with critical temperature is then compared to explore their comparative temperature dependence trends.

Then, the dependence of flame times on pressure is investigated and compared with that of ignition delay times of $\mathrm{CH}_{4}$ by comparing their variation trends with temperatures at pressures of $1,5,10$, and 20 bars and various equivalence ratios. To quantify the pressure and equivalence ratio dependence of flame times and ignition delay, a power law in the form $\tau \propto p^{m} \phi^{n}$ is used. The exponents $m$ and $n$ are obtained using separate correlations for both flame times and ignition delay times in the form:

$$
\tau=C p^{m} \phi^{n} \exp \left(\frac{E_{a}}{R T_{c r}}\right)
$$

where $\tau$ is the flame time/ignition delay time in microseconds, $p$ is the pressure in bar, $\phi$ is the equivalence ratio, $E_{a}$ is the global activation energy in $\mathrm{kcal} / \mathrm{mol}, R$ is the universal gas constant in $\mathrm{kcal} / \mathrm{mol} \cdot \mathrm{K}$, and $T_{c r}$ is the critical temperature in Kelvin. Multiple linear regression is then applied to the logarithmic form of the previous correlation to obtain the exponents as follows:

$$
\ln (\tau)=\ln (C)+m \ln (p)+n \ln (\phi)+\frac{E_{a}}{R T_{c r}}
$$

Flame times and ignition delay times for $\mathrm{CH}_{4}$ are then compared directly in order to develop a correlation between both times using all simulation results at the pressures, temperatures, and equivalence ratios mentioned earlier. The purpose of such a correlation is enabling the prediction of flame times, and therefore laminar burning velocities for $\mathrm{CH}_{4}$, from ignition delay times.

To establish that flame time can be used to establish comparative flame propagation trends in the same way ignition delay time is used to compare fuel reactivity, flame times of $\mathrm{CH}_{4}$ are compared with those for propane $\left(\mathrm{C}_{3} \mathrm{H}_{8}\right)$, a more complex linear alkane compared with methane, and ethanol $\left(\mathrm{C}_{2} \mathrm{H}_{5} \mathrm{OH}\right)$, a representative transportation biofuel, at similar pressure and equivalent ratio conditions. Simulations for propane are performed following the same procedure and using the aforementioned model by Petersen et al. ${ }^{24}$ Ethanol simulations are based on the chemical kinetic model by Marinov. ${ }^{25}$ 


\section{RESULTS}

In this part, the results of the comparative parametric study for flame time and ignition delay time are shown and analyzed in the manner described in the previous section. The variation of flame time and ignition delay time with critical temperature for methane is explored next.

\section{Temperature Dependence}

Temperature variation trends are explored for both flame time and ignition delay time simulations for methane/air mixtures using the model by Petersen et al. $^{26}$ at pressures of $1.0-20$ bars, equivalence ratios of $0.75-1.25$, and unburnt temperature range of 300-1000 K. Figure 1 shows examples of such comparative trends.
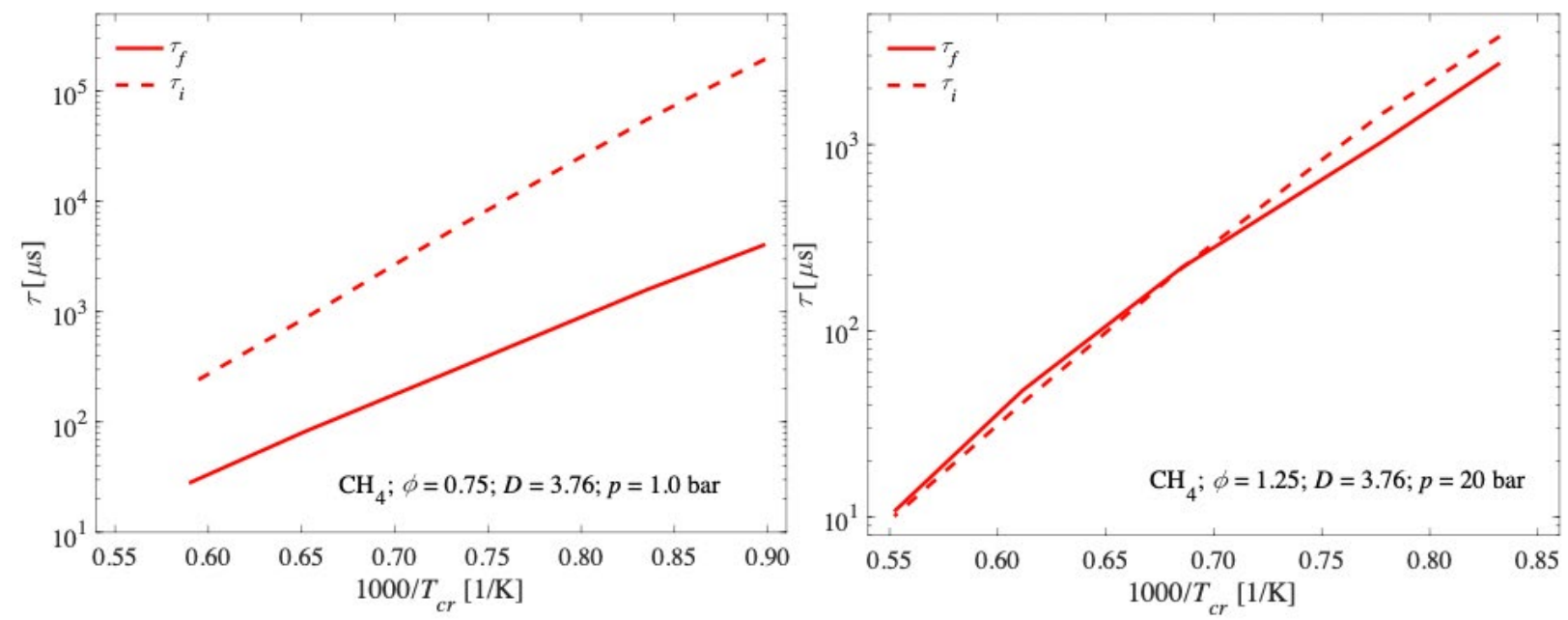

Figure 1. Flame Time and Ignition Delay Time Variation with Critical Temperature for Methane/Air Mixtures (at pressures of 1.0 and 20 bars and equivalence ratios of 0.75 and 1.25 )

Figure 1 shows Arrhenius temperature dependence profiles for both flame time and ignition delay time; both times are observed to increase with decreasing temperature. Figure 1 also reveals that ignition delay times tend to be substantially longer than flame times at lower pressures. However, ignition delay times approach flame times at higher temperatures. A cross-over effect is observed at a pressure of 20 bars for critical temperatures above $1470 \mathrm{~K}$.

The observations suggest that while both times exhibit pressure dependence, ignition delay time has relatively stronger dependence on pressure than flame time. Therefore, the next part will focus on exploring pressure and equivalence ratio dependence of flame time and ignition delay time.

\section{Pressure and Equivalence Ratio Dependence}

Investigation of the pressure and equivalence ratio dependence of flame times and ignition delay times is carried out by comparing calculated flame times and simulated ignition delay times for methane/air mixtures at various pressures at the same equivalence ratios and unburnt temperature ranges. Estimated flame times for methane/air mixture at pressures 
of $1.0,5.0,10$ and 20 bars and equivalence ratios of 0.75 and 1.25 are shown in Figure 2. Simulated ignition delay times at the same pressure and equivalence ratio conditions are shown in Figure 3.
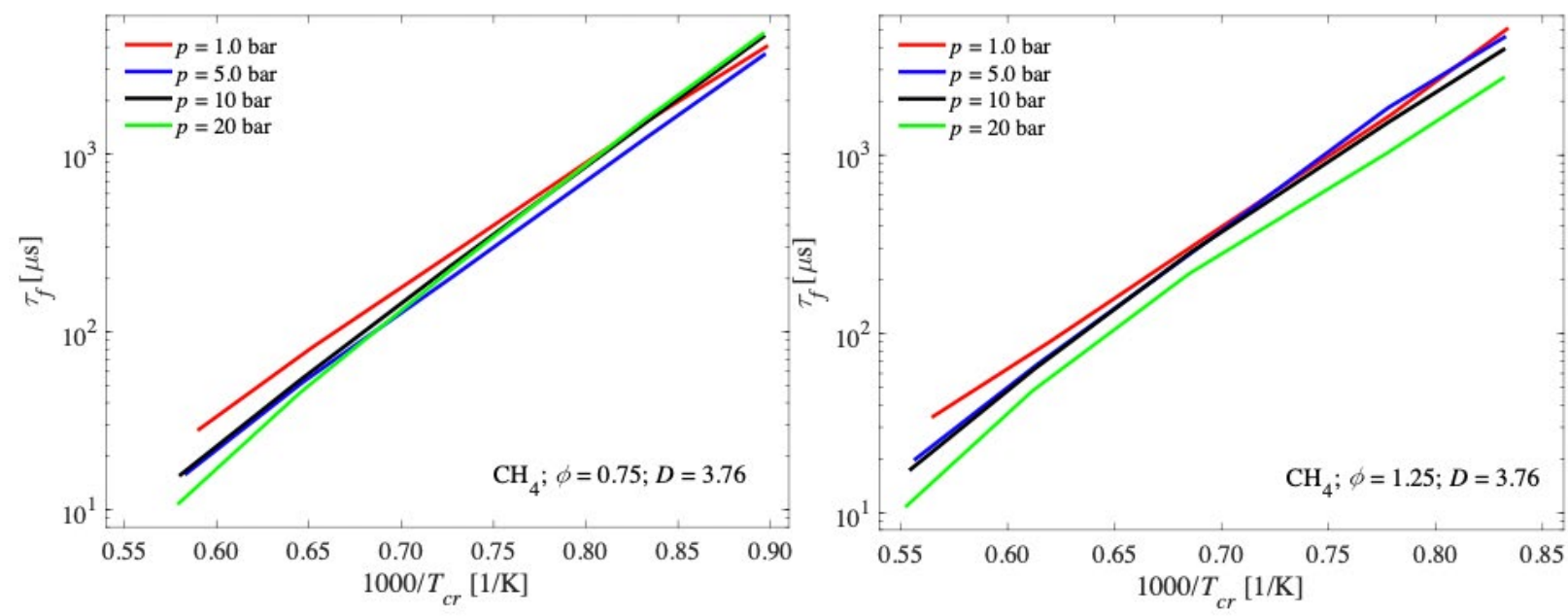

Figure 2. Flame Time Pressure Dependence of Methane/Air Mixtures at Pressures of 1.0-20 Bars and Equivalence Ratios of 0.75 and 1.25
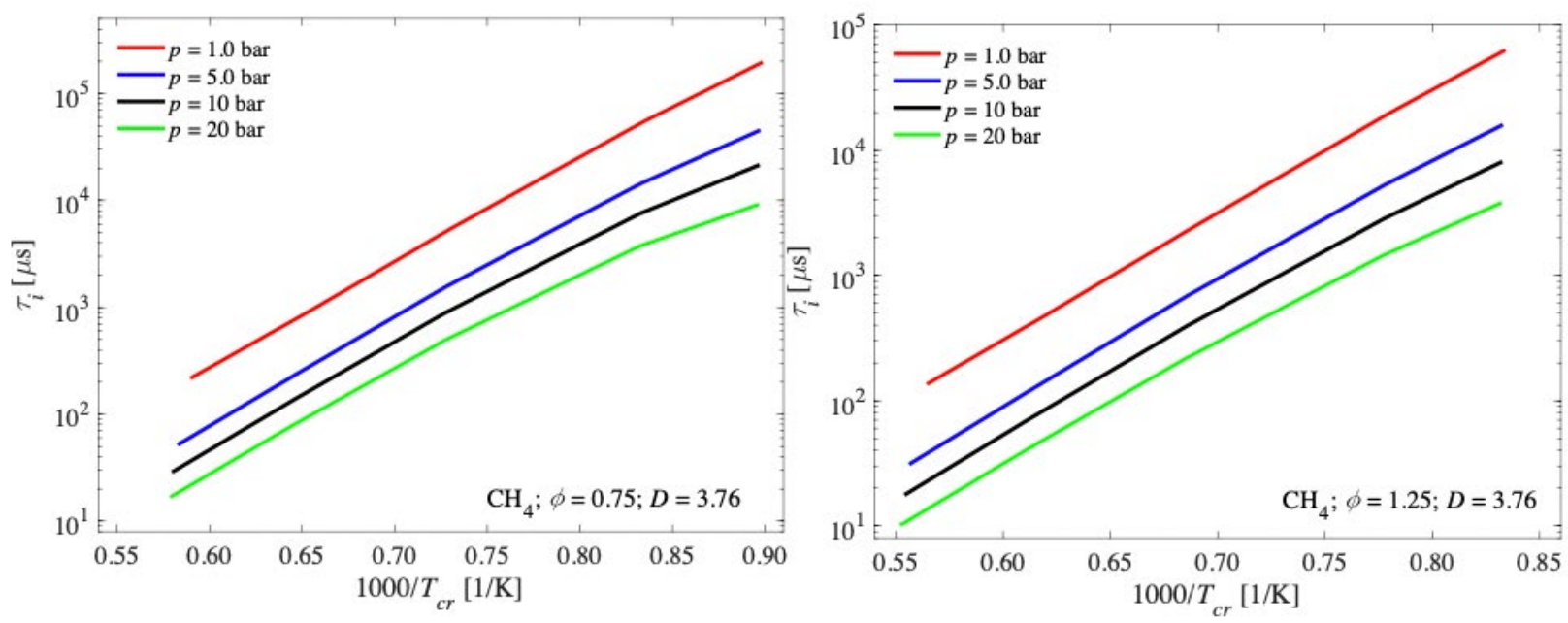

Figure 3. Ignition Delay Time Pressure Dependence of Methane/Air Mixtures at Pressures of 1.0- 20 Bars and Equivalence Ratios of 0.75 and 1.25

Figure 2 shows the pressure variation profile of methane flame times, showing that flame times become shorter at higher pressures for high critical temperatures at all equivalence ratios. However, it shows a reversed pressure dependence profile for lean mixtures at lower critical temperature, with multiple cross-over effects observed among all four pressures. The same effect is observed for stoichiometric mixtures. A similar behavior is observed at rich conditions, with shortest flame times consistently observed at a pressure of 20 bar.

Figure 3 shows that the pressure dependence of ignition delay time is much stronger than that of flame time, in line with the earlier observation from Figure 2. Ignition delay time become consistently shorter as pressure increases, and therefore mixture becomes more reactive 
The pressure and equivalence ratio dependence for flame time and ignition delay time is then quantified. Multiple linear regression is used to develop a correlation in the form of equation for simulated flame times and ignition delay times for methane/air mixture at pressures of 1.0-20 bar and equivalence ratios of $0.6-1.6$, and to estimate pressure and equivalence ratio exponents for both times, which can reveal the direction and strength of the correlation with both parameters.

For flame time, the regression yields a pressure dependence exponent of -0.17 , compared with -0.83 for ignition delay time. This is consistent with the observations from Figure 2 and Figure 3, confirming the overall trend that both times decrease with increasing pressures, and revealing that ignition delay time is more significantly dependent on pressure than flame time. Increasing pressure reduces both flame time and ignition delay time, with a more significant reduction observed in ignition delay time.

The opposite behavior is observed in the case of equivalence ratio. The regression yields an equivalence ratio exponent of 0.97 for flame time, while for ignition delay time the exponent is 0.22 . This reveals a positive relationship between equivalence ratio and flame time, with slower flame propagation for richer mixtures. Opposite to the pressure effect, the equivalence ratio effect on flame time is much stronger than that on ignition delay time.

Therefore, the effect of pressure on auto-ignition behavior is more pronounced, while flame propagation is more significantly controlled by equivalence ratio than by pressure. Equation (6) shows the flame time correlation and equation (7) shows the ignition delay time correlation for methane/air mixtures.

$$
\begin{gathered}
\tau_{f}=1.004 \times 10^{-3} p^{-0.17} \phi^{0.97} \exp \left(\frac{18002.4}{T_{c r}}\right) \\
\tau_{i}=1.084 \times 10^{-3} p^{-0.83} \phi^{0.22} \exp \left(\frac{21138.6}{T_{c r}}\right)
\end{gathered}
$$

These correlations can be used to estimate flame times and ignition delay times from the combustion event conditions of pressure, temperature, and equivalence ratio. Raw data at multiple pressures and equivalence ratios can also be scaled using these correlations for overall reactivity and flame propagation trend exploration.

\section{Flame Time and Ignition Delay Time Correlation}

After performing the parametric dependence investigation for flame times and ignition delay times, the direct relationship between the two characteristic times is explored. This in order to achieve one of the main purposes of this work, which is enabling the prediction of laminar burning velocity from ignition delay time knowledge. 


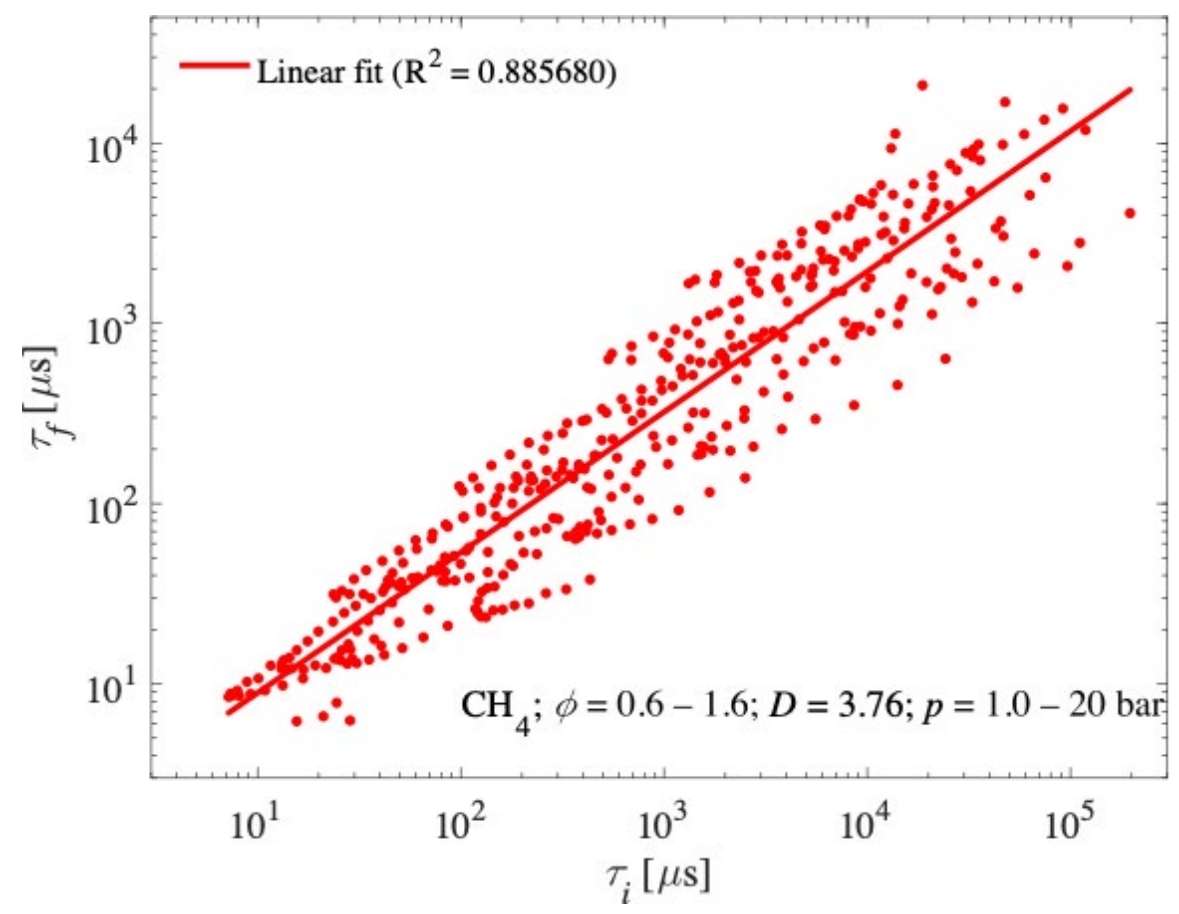

Figure 4. Flame Times versus Ignition Delay Times for Methane/Air Mixtures at Pressures of 1.0-20 Bar and Equivalence Ratios of 0.6-1.6

Figure 4 shows the fitting of raw flame time and ignition delay time simulation data for methane/ air mixtures at pressures of 1.0-20 bar, equivalence ratios of 0.6-1.6, unburnt temperatures of $300-1000 \mathrm{~K}$, and a dilution ratio of 3.76 . The linear trend line shows a positive relationship between the logarithms of both times, with a coefficient of determination $\left(R^{2}\right)$ of 0.8857 . A relatively strong positive linear correlation is observed between the logarithms of flame time and ignition delay time. A correlation between the two characteristic times can be developed in a logarithmic form as follows:

$$
\ln \left(\tau_{f}\right)=0.3919+0.7794 \ln \left(\tau_{i}\right)
$$

Converting the logarithmic form into a power law correlation between the two times yields the following expression:

$$
\tau_{f}=1.4789 \tau_{i}^{0.7794}
$$

\section{Comparative Flame Time Trends Among Various Fuels}

Flame time predictions of three different fuels are now compared to reveal their comparative flame propagation trends. Methane, the main fuel of this study, is compared with propane, a representative $n$-alkane, and ethanol, a representative alcohol and commonly used transportation biofuel. This comparison is aimed at establishing the possibility of using flame times to establish comparative flame propagation trends among fuels in the same way comparative reactivity trends are revealed from ignition delay times. 

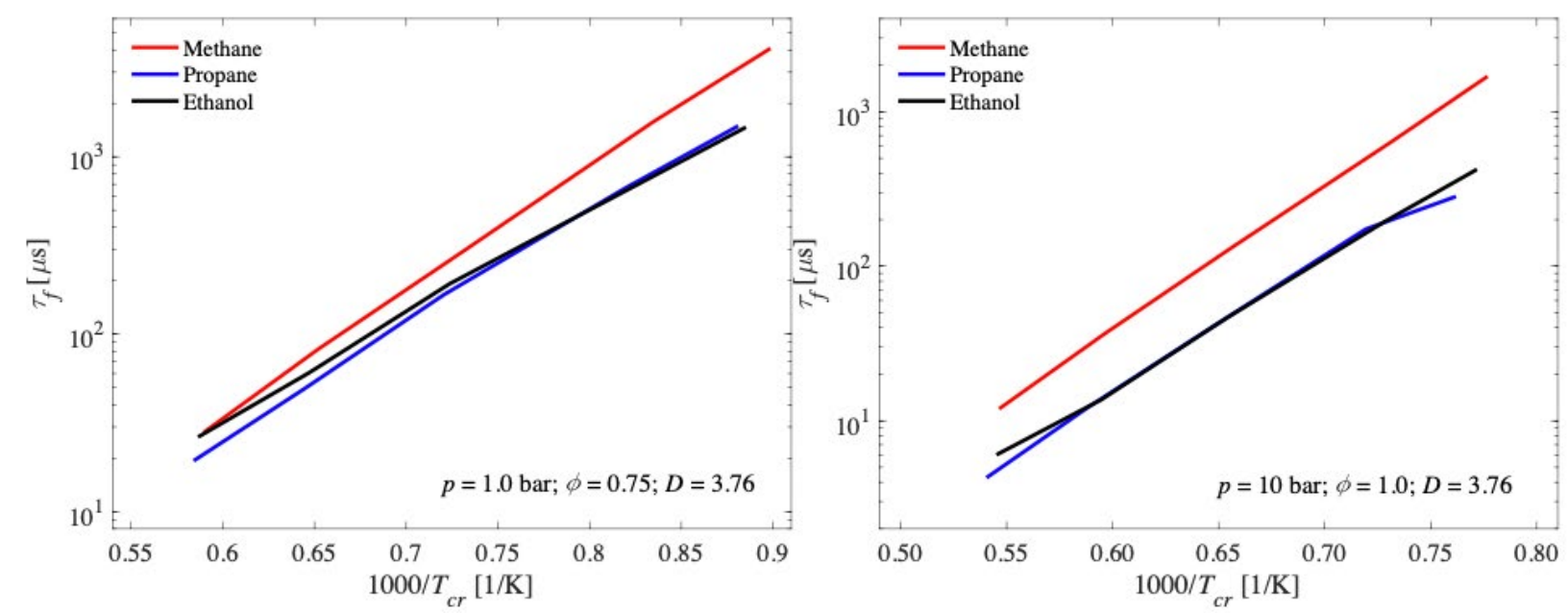

Figure 5. Flame Times of Methane, Propane, and Ethanol Mixtures with Air at Pressures of 1.0 and 10 Bars and Equivalence Ratios of 0.75 and 1.0

Comparative flame time trends are explored for mixtures of methane, propane, and ethanol with air, predicted from their respective models, ${ }^{27}$ at pressures of 1.0, 10, and 20 bar, equivalence ratios of $0.75,1.0$, and 1.25 , and a dilution ratio of 3.76 . Figure 5 shows the comparative trends at sample conditions. At all conditions, methane consistently exhibits the longest flame times, and therefore it can be characterized with the slowest flame propagation among the three fuels.

On the other hand, propane and ethanol exhibit similar flame time trends in most investigated conditions. Multiple cross-over events are observed between the two trends. Moreover, Figure 5 shows the possibility of a cross-over between methane and ethanol at low pressures and critical temperatures above $1700 \mathrm{~K}$. This indicates that ethanol may have the slowest flames at near atmospheric pressures and higher unburnt gas temperatures.

\section{DISCUSSION}

A novel investigation approach is implemented to explore the possibility of establishing a link between two separate combustion problems, namely, auto-ignition and flame propagation. The investigation resulted in the development of a power law correlation between the time scales representing the aforementioned problems.

Since the main goal for this part of the investigation is the development of a way to establish such a link, the findings of this work should be interpreted in the context of being an exploratory effort that tests if it would be possible to link two completely different combustion problems. This work managed to present a process that leads to establishing a direct relationship between flame time and ignition delay time for a specific fuel. Such a process can be followed by researchers to develop a similar link for any fuel of interest, which would in turn support future efforts for simultaneous simulation of ignition delay time and laminar burning velocity. In addition, the parametric dependence correlation reveals the nature of parametric dependence of flame time compared with that of a more commonly used combustion time scale, which is ignition delay time. 
Therefore, future researchers can utilize the process demonstrated in this work to find a direct relationship between flame time and ignition delay time for any fuel of interest, as this study succeeded in establishing a direct relationship between the two times. However, researchers should exercise caution during the use of the developed correlation for methane or any similar correlation resulting from this process for any fuel. The developed power law is based on simulations of laminar burning velocity and ignition delay time for a specific fuel, methane in this case. Therefore, its use for the prediction of laminar burning velocities from ignition delay time would be limited to that fuel, within the ranges of temperature, pressure, and equivalence ratio at which the simulations were performed, as is the case with any regression-based correlations.

While the developed correlations are fuel-specific, the process itself is generalizable and can be used for any fuel of interest, depending on the availability of chemical kinetic models, thermodynamic data, and transport parameters for that fuel. 


\section{THF MODEL REDUCTION AND ANALYSIS}

\section{METHODOLOGY}

In this work, a straightforward model reduction approach will be adopted, which is the newly developed Stochastic Species Elimination (SSE) method, ${ }^{28}$ a modification of the speciessensitivity-based Alternate Species Elimination (ASE) method. ${ }^{29}$ The SSE method identifies the important species by testing the effect of removing the reactions containing a given species on the prediction of a combustion property such as ignition delay time. This is achieved using the CANTERA software package by setting the reaction rate multiplier of the reactions containing the tested species to zero. The process can be automated over all species in a given model. SSE also features random sampling of the species, which eliminates the dependence on the "order" of the species in the detailed model. The SSE approach is linear, and a smaller model can be obtained at any stage of the reduction by terminating the reduction process upon reaching a desired level of reduction.

For small and medium sized mechanisms ( $<1000$ species), the standard SSE procedure can be employed. For larger mechanisms (>1000 species), a multi-stage, multi-species SSE approach can be employed by testing randomly generated groups of species, rather than single species. The SSE method has shown superior performance compared to its predecessor, the ASE method, with up to $34 \%$ reduction in the computational time required for model reduction. ${ }^{30}$

The Stochastic Species Elimination (SSE) model reduction approach ${ }^{31}$ is implemented in this work using CANTERA chemical kinetic software package to develop multiple skeletal versions of a detailed chemical kinetic model of tetrahydrofuran (THF) ${ }^{32}$ based on ignition delay time simulations at various pressures and temperature ranges. The detailed THF model contains 441 species and 2470 reactions. The developed skeletal versions are combined into an overall reduced model of THF. Ignition delay time and laminar burning velocity simulations are performed using detailed and reduced models to explore the agreement of the predictive performance of the reduced version(s) with that of the detailed model.

Then, reaction sensitivity analysis is then performed in CANTERA to identify the most important reactions responsible for the performance of the reduced model. This analysis is performed by multiplying the reaction rate of each reaction by ten, then observing the effect of speeding up the specific reaction on the prediction of ignition delay time. For the reactions identified as important, reaction rate parameter modification is performed in order to improve the agreement of detailed and reduced model predictions with experimental ignition data from the literature. Original reaction rate parameters are replaced with other values from the literature for the exact reactions or analogous reactions of the same type. The choice of values from the literature takes into account whether the reaction needs to be expedited or slowed down, based on the results of the sensitivity analysis. Finally, the modified version of the reduced model will be tested in ignition delay time and laminar burning velocity simulations to verify that the modification worked in the desired direction. 


\section{RESULTS}

\section{Reduction Process}

Using the SSE technique mentioned earlier in the previous section, multiple runs of reduction were performed for the THF model by Fenard et al. ${ }^{33}$ which contains 441 species and 2470 species. The reduction runs were carried out under a pressure range of 7.7-20 bar and a temperature range of $750-1200 \mathrm{~K}$. This is in order to produce different reduced versions of the detailed model that captures various chemical kinetic profiles of high and low temperature combustion at different pressures. This process resulted in the development of seven reduced versions of the original THF model, with a number of species ranging from 120 to 130 species and a number of reactions between 600 and 650 .

Then, a global skeletal model is developed from the seven reduced versions previously developed. The species and reactions of the seven reduced versions are combined into a single model after excluding duplicate common species and reactions. This process results in a global skeletal version containing 1151 reactions among 193 species. The purpose of this step is developing a global version that captures the combustion chemistry of a wider range of pressure and temperature conditions while achieving a significant model size reduction compared with the detailed version.
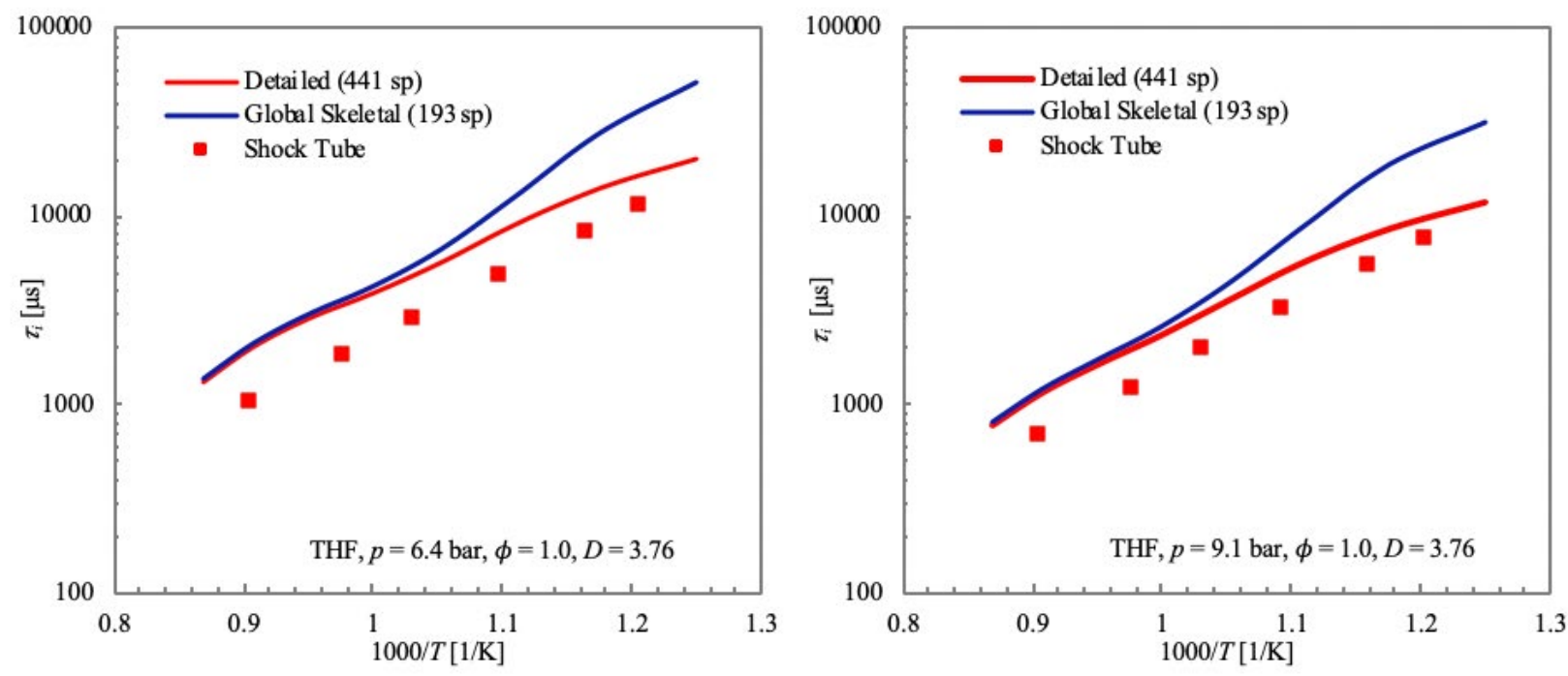

Figure 6. Comparison of Ignition Delay Simulations using the Global Skeletal and Original THF Detailed Models with Shock Tube data ${ }^{34}$ for Stoichiometric THF/Air Mixtures at Pressures of 6.4 and 9.1 Bar

Ignition delay time simulations are carried out using the global skeletal model and the original detailed model for THF/air mixtures at stoichiometric conditions and pressures of 6.4 and 9.1 bar, as shown in Figure 6. The ignition delay time predictions are compared with experimental ignition delay time measurements reported by Fenard et al. ${ }^{35}$ at the same conditions. Figure 6 shows that both versions of the model tend to over-estimate ignition delay times compared with experimental data. The predictive performance of the skeletal versions has good agreement with the detailed versions at temperatures over $1000 \mathrm{~K}$ at all pressure conditions. However, as temperature decreases, deviations 
between both versions become more significant, indicating that the reduction process resulted in eliminating some important reaction pathways in the low temperature region.

\section{Sensitivity Analysis}

To explore the main reactions responsible for the observed behavior, brute-force reaction sensitivity analysis is performed for both versions. First, the reaction sensitivity of both versions is compared at an intermediate temperature of $1000 \mathrm{~K}$ and a pressure of $9.1 \mathrm{bar}$. The effect of each reaction on the ignition delay time prediction at this condition is investigated by multiplying the reaction rate constant for each reaction by 10 , proceeding one reaction at a time, and a logarithmic sensitivity factor is calculated for each reaction and compared, as shown in Figure 7.

The sensitivity analysis reveals that the three most sensitive reactions in both versions are the ring opening of the tetrahydrofuran-3-yl radical (Cy(OCCJCC) in the model), in addition to two termination reactions involving $\mathrm{O}, \mathrm{H}$, and $\mathrm{OH}$ radicals. These three reactions exhibit positive sensitivity coefficients, indicating that they inhibit reactivity at these conditions. Another important reaction in both versions is the branching reaction between atomic hydrogen and molecular oxygen, with a negative sensitivity coefficient that indicates a reactivity enhancing behavior, which is expected as this reaction results in the production of free radicals of $O$ and $\mathrm{OH}$, and therefore this production leads the chain reaction to proceed at a faster rate.

However, some deviations between the skeletal and detailed models can be observed from Figure 7. It shows that the bimolecular initiation reaction $\mathrm{C}_{3} \mathrm{H}_{6}+\mathrm{O}_{2} \leftrightarrow \mathrm{C}_{3} \mathrm{H}_{5}-\mathrm{a}+\mathrm{HO}_{2}$ and the subsequent termination reaction of the allyl radical $\left(\mathrm{C}_{3} \mathrm{H}_{5}-\mathrm{a}\right)$ to form 1-butene $\left(\mathrm{C}_{4} \mathrm{H}_{8}-1\right)$ are sensitive and reactivity inhibiting in the skeletal model only, while this pathway does not appear to be significant in the predictions of the detailed model. On the other hand, a number of branching reactions involving ethylenyl radical $\left(\mathrm{C}_{2} \mathrm{H}_{3}\right)$ production or consumption are observed to only be significant in the detailed version. The isomerization reaction of the tetrahydrofuran-3-peroxy radical (denoted JOOcy (CCOCC) in the model) through $\mathrm{H}$-atom shift from gamma position is also significant in the detailed version only with a reactivity enhancing effect. 


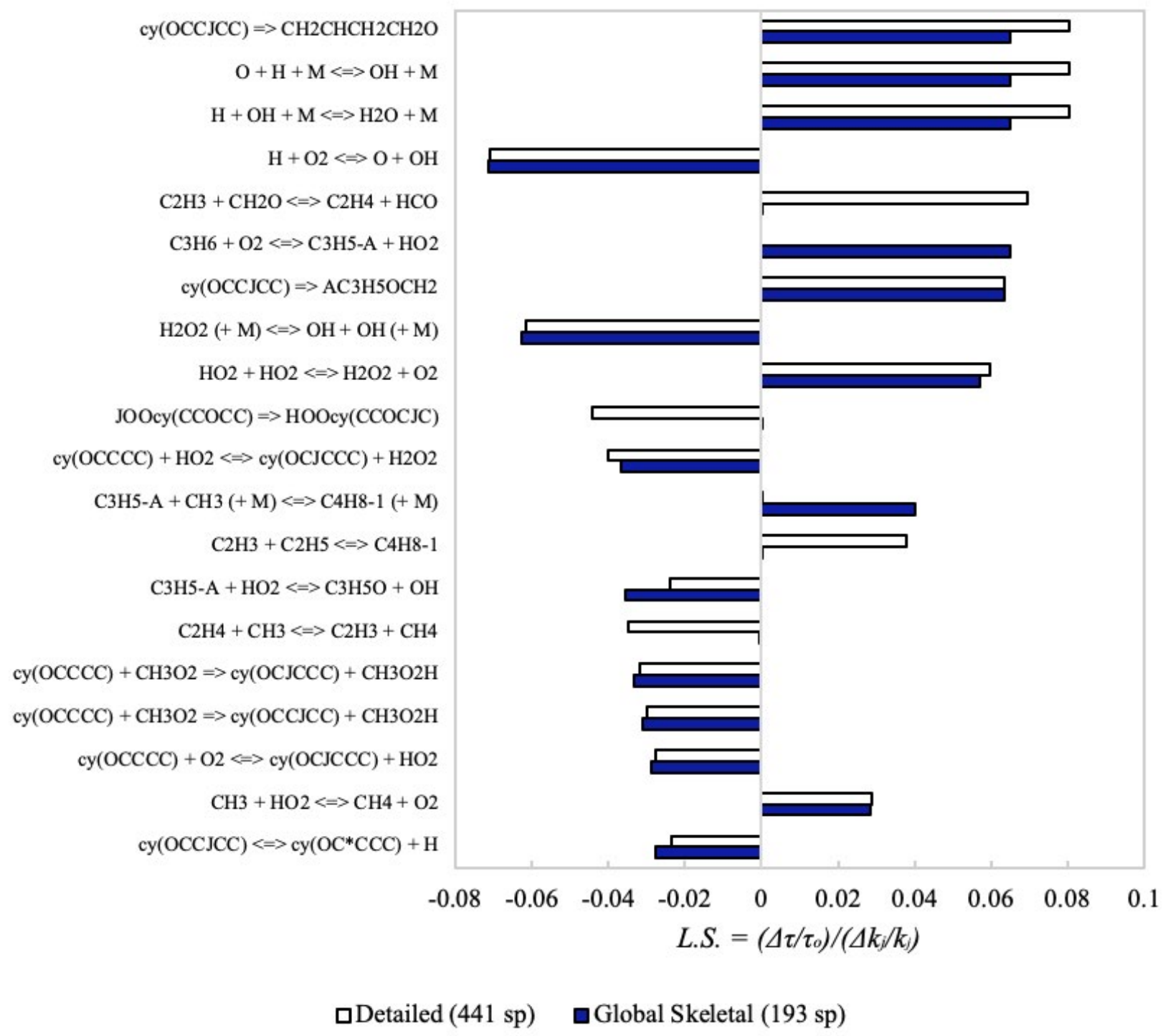

Figure 7. Brute-force Reaction Sensitivity Analysis using Detailed and Global Skeletal Versions for Stoichiometric THF/Air Mixture at 9.1 Bar and $1000 \mathrm{~K}$

It is also informative to explore the most important reactions from the skeletal model perspective, but at different temperature ranges, to explore and understand the relevant combustion pathways as temperature varies. This is particularly important to identify the pathways that lead to the observed deviation between skeletal and detailed models at lower temperatures. For this purpose, sensitivity analysis is performed using the skeletal model at a pressure of 9.1 bar and a low temperature of $700 \mathrm{~K}$, an intermediate temperature of 1000 $\mathrm{K}$, and a high temperature of $1300 \mathrm{~K}$, as shown in Figure 8.

The reaction $\mathrm{H}+\mathrm{O}_{2} \leftrightarrow \mathrm{O}+\mathrm{OH}$ is observed to be the most sensitive reaction with a reactivity enhancing effect for intermediate and high temperatures, with very low importance at low temperatures. This indicates that the formation of a radical pool is a significant pathway at intermediate and high temperatures, while low temperatures do not favor this pathway, suggesting a more pyrolytic reaction pathway for THF at low temperatures. The results also show that $\mathrm{H}$-abstraction from THF favors the formation of the tetrahydrofuran-2-yl radical 
(denoted cy(OCJCCC) in the model) over its isomer tetrahydrofuran-3-yl. This may indicate that enhancing the importance of the pathways leading to tetrahydrofuran-3-yl production at low temperatures can lead the skeletal model to predict higher reactivity at these conditions.

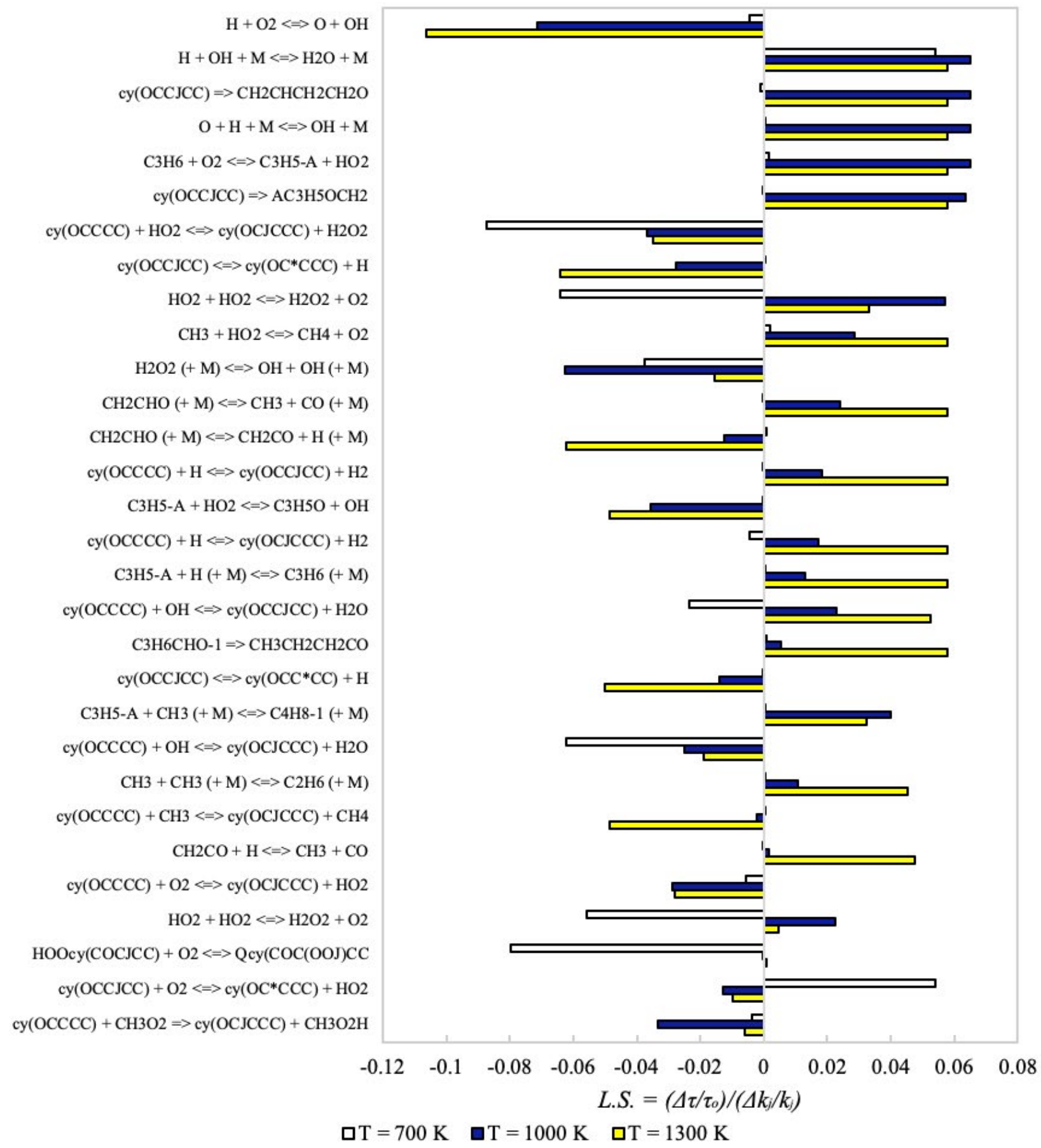

Figure 8. Brute-force Reaction Sensitivity Analysis using Skeletal Model for Stoichiometric THF/Air Mixture at 9.1 Bar and Temperatures of 700, 1000, and $1300 \mathrm{~K}$

At low temperatures, $\mathrm{H}$-abstraction from THF is carried out mostly by the hydroperoxyl radical $\left(\mathrm{HO}_{2}\right)$, while $\mathrm{H}$-abstraction by the hydroxyl radical $(\mathrm{OH})$ is more significant at higher temperatures as more $\mathrm{OH}$ is produced during initiation. The combination of hydroperoxyl radicals to form hydrogen peroxide $\left(\mathrm{H}_{2} \mathrm{O}_{2}\right)$ and molecular oxygen is a reactivity enhancing 
reaction at low temperatures, while having a mild opposite effect at higher temperatures. Addition of molecular oxygen to the 2-hydroperoxytetrahydrofuran radical (denoted HOOcy(COCJCC) in the model) is very significant and reactivity enhancing at lower temperatures as well, while the $\mathrm{H}$-abstraction from tetrahydrofuran-3-yl by $\mathrm{O}_{2}$ inhibits reactivity at the same conditions.

\section{Reaction Rate Parameter Modification and Testing}

Based on the results of the previous brute-force reaction sensitivity analyses, the most significant reactions leading to the observed ignition delay time predictions are identified for the skeletal and detailed THF models at various conditions. The reaction rate parameters of such reactions can be modified by replacing them with values from the literature for the same reaction or for analogous reactions if reaction-specific data are unavailable. The goal is enhancing the predictive performance of the small skeletal model to match or even exceed the performance of the larger detailed model. Therefore, the desired result would be a smaller model with same or better performance than the original.

The reaction rate constant decides how fast a reaction occurs and therefore how important a pathway passing by a specific reaction is. Reaction rate constant is calculated using the Arrhenius equation as follows:

$$
k=A\left(\frac{T}{298}\right)^{n} e^{\frac{-E a}{R T}}
$$

where $A$ is the pre-exponential factor representing collision frequency, Ea is the activation energy of the reaction, $n$ is the temperature coefficient, $R$ is the universal gas constant, and $T$ is the temperature. $A, n$, and Ea are the aforementioned reaction rate parameters. A series of reaction rate parameter modifications is applied to the skeletal model and listed in TTable 1.

The reaction rate parameters for five reactions are modified with values from the literature. The reactions chosen for modification are identified from the sensitivity analysis as reactivity enhancing, especially at lower temperatures where the predictive performance of the skeletal model significantly deviates from that of the detailed model. Reaction rate parameters are updated with values that result in higher reaction rate constants, which means these reactions are accelerated and their priority in the chain reaction is elevated. As a result, the reactivity of the mixture is increased by these modifications, potentially leading to faster ignition and shorter ignition delay times. Out of the five reactions, four of them are $\mathrm{H}$-abstraction from THF by hydroxyl and hydroperoxyl radical as well as molecular oxygen to produce tetrahydrofuran-2-yl and tetrahydrofuran-3-yl radicals, necessary for chain reaction continuation. The fifth reaction to be prioritized is the third body decomposition of hydrogen peroxide to provide the mixture with a pool of hydroxyl radical, needed for $\mathrm{H}$-abstraction from THF as shown above. 
Table 1. Updated Reaction Rate Parameters Applied to the Skeletal THF Model (Reactions as shown in model).

\begin{tabular}{lllllll}
\hline \multicolumn{1}{c}{ Reaction } & \multicolumn{1}{c}{$\begin{array}{c}\mathbf{A}_{\text {new }} \\
\left(\mathbf{c m}^{3} / \mathbf{s} . \mathbf{m o l}\right)\end{array}$} & $\mathbf{n}_{\text {new }}$ & $\begin{array}{c}\mathbf{E a}_{\text {new }} \\
(\mathbf{c a l} / \mathbf{m o l})\end{array}$ & $\begin{array}{c}\mathbf{A}_{\text {old }} \\
\left(\mathbf{c m}^{3} / \mathbf{s} . \mathbf{m o l}\right)\end{array}$ & $\mathbf{n}_{\text {old }}$ & $\begin{array}{c}\mathbf{E a}_{\text {old }} \\
(\mathbf{c a l} / \mathbf{m o l})\end{array}$ \\
\hline $\mathrm{cy}(\mathrm{OCCCC})+\mathrm{O} 2 \leftrightarrow \mathrm{cy}(\mathrm{OCJCCC})+\mathrm{HO}^{\mathrm{a}}$ & $5.2 \mathrm{e} 13$ & 0.00 & 45800 & $1.34 \mathrm{e} 13$ & 0.00 & 45640 \\
$\mathrm{cy}(\mathrm{OCCCC})+\mathrm{OH} \leftrightarrow \mathrm{cy}(\mathrm{OCJCCC})+\mathrm{H}_{2} \mathrm{O}^{\mathrm{b}}$ & $1.3 \mathrm{e} 13$ & 0.33 & -330 & $6.93 \mathrm{e} 11$ & 0.41 & 213.6 \\
$\mathrm{cy}(\mathrm{OCCCC})+\mathrm{OH} \leftrightarrow \mathrm{cy}(\mathrm{OCCJCC})+\mathrm{H}^{\mathrm{a}} \mathrm{O}^{\mathrm{a}}$ & $9.4 \mathrm{e} 7$ & 1.61 & -35 & $4.12 \mathrm{e} 3$ & 3.02 & -913.8 \\
$\mathrm{cy}(\mathrm{OCCCC})+\mathrm{HO} 2 \leftrightarrow \mathrm{cy}(\mathrm{OCCJCC})+\mathrm{H}_{2} \mathrm{O}^{\mathrm{a}}$ & $2.52 \mathrm{e} 2$ & 3.37 & 13700 & $7.21 \mathrm{e}-2$ & 4.13 & 11460 \\
$\mathrm{H} 2 \mathrm{O} 2(+\mathrm{M}) \leftrightarrow \mathrm{OH}+\mathrm{OH}(+\mathrm{M})^{\mathrm{c}}$ & $1.21 \mathrm{e} 17$ & 0.00 & 45500 & $2.0 \mathrm{e} 12$ & 0.90 & 48749 \\
\hline
\end{tabular}

a Moshammer et al. ${ }^{36}$

b Zavala-Oseguera et al. ${ }^{37}$

c Baulch et al. ${ }^{38}$

The final modified skeletal version containing 193 species and 1151 reactions is now tested during ignition delay time simulations versus the unmodified skeletal model and original detailed model for THF/air mixtures at stoichiometric conditions and pressures of 6.4 and 9.1 bar, as shown in Figure 9. The results show that the final skeletal model exhibits superior predictive performance to both the unmodified skeletal version and the larger detailed model at almost all investigated conditions. The skeletal model after modification is successfully reproducing the experimentally measured ignition delay times over the temperature ranges investigated. As the temperature decreases, slight deviations with the shock tube data are observed, but these deviations match those of the detailed model. Therefore, the final skeletal model is overall better-performing than the detailed model, at less than half the size, and therefore it carries much lower computational cost.
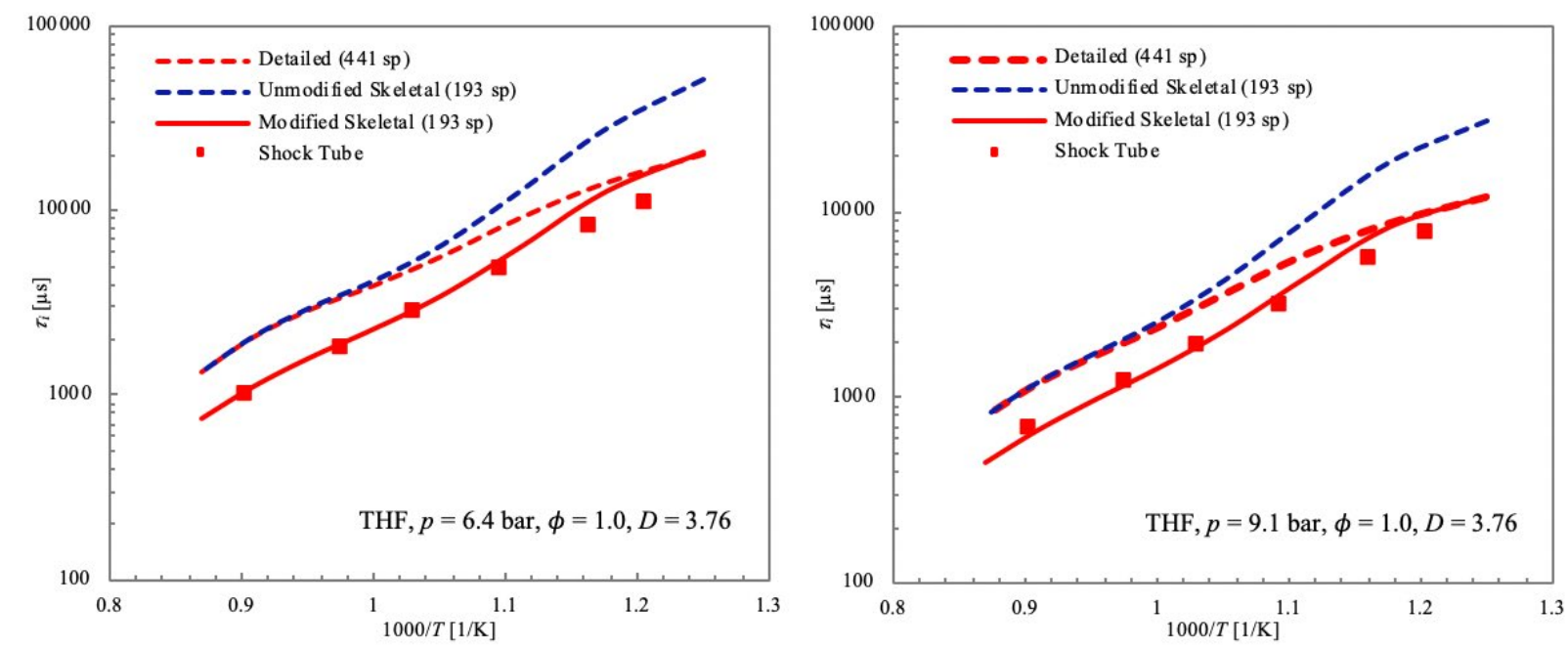

Figure 9. Predictions of Modified Skeletal Model with Unmodified Skeletal Model (original THF detailed model and shock tube measurements by Fenard et al. ${ }^{39}$ for stoichiometric THF/air mixtures at pressures of 6.4 and 9.1 bar) 


\section{DISCUSSION}

First of all, it is crucial to understand that model reduction is not the end goal per se, but merely a step towards faster and less computationally expensive simulations of combustion events, while preserving the predictive accuracy to the maximum possible extent. In light of these considerations, this work uses the SSE model reduction method to further our understanding of the auto-ignition behavior of THF and the underlying chemical kinetics. This is ultimately aimed at enhancing the performance of the developed skeletal THF model so that it can be superior to the larger original version, and hence achieving better agreement with experimentally observed auto-ignition trends.

The findings of this part of the investigation reveal that the SSE reduction approach succeeded in downsizing the original THF model to less than half its size, eventually leading to the reduction in the computational cost of the simulations because of the significant reduction in the number of the ordinary differential equations to be solved simultaneously by the chemical kinetic solver. With respect to the predictive performance, it can be observed that the initial unmodified version of the reduced model significantly overestimated ignition delay times, especially at lower temperatures. Longer ignition delay times mean that the fuel used is less reactive than what was observed experimentally. Given that the detailed model was originally developed for low-temperature simulations, ${ }^{40}$ it can be expected that excluding over half of the species and reactions would lead the predictive performance to suffer at this temperature range.

However, one of the upsides of the reduction process is that it facilitates performing chemical kinetic analysis using smaller models to obtain insights about the combustion kinetics responsible for the observed predictive performance. For this purpose, reaction sensitivity analysis was performed at various temperatures to identify and compare the main reactions and pathways that caused the observed performance of the reduced model. Overall, the formation of radicals accelerates the chain reaction as unstable radicals are very reactive, and therefore they attack stable molecules, especially those for THF. This eventually leads to a faster consumption of the fuel and a faster chain reaction.

The sensitivity analysis shows that the existing reaction mechanism favors $\mathrm{H}$-abstraction from THF by radicals such as $\mathrm{OH}$ at higher temperatures, while this pathway is not favored at lower temperature, as $\mathrm{H}$-abstraction using $\mathrm{HO} 2$ radical appears to be more significant. Therefore, the lower production rate of the $\mathrm{OH}$ radical at lower temperatures can be a main reason behind the observed significantly longer ignition delay times at these conditions.

Adjusting the reaction rates for reactions producing $\mathrm{OH}$ and $\mathrm{HO} 2$ so that more of these radicals is produced would open alternate consumption pathways for THF, eventually increasing the rate of THF consumption so that it can ignite faster, matching the experimentally observed trends. Therefore, reaction rate parameters were adjusted for 5 reactions using values from the literature, including $\mathrm{OH}$ and $\mathrm{HO} 2$ formation reactions and $\mathrm{H}$-abstraction reactions from THF using the formed radicals, in the direction that enhances the overall reactivity, eventually leading to shorter ignition delay times to achieve better agreement with experimental data. The modifications succeeded in improving this agreement with shock tube ignition data, and therefore the final modified 
skeletal model now has generally better predictive performance than the original detailed model, especially at lower temperatures.

Finally, the process shows the power of model reduction approaches, especially the SSE approach used in this work. Performing this kind of in-depth analysis using detailed model is usually time-consuming and requires significant computational resources. By reducing the size of models, such analysis can be performed in a fraction of the time, which makes enhancing the performance of models based on the results of such analysis more accessible. The process presented in this work can be applied to any chemical kinetic model for any fuel or blend of fuels of interest for the purpose of improving understanding and model performance. 


\section{CONCLUSION AND FUTURE RESEARCH}

This work is an attempt to address some challenges facing combustion modeling, such as the need to use separate reactor models for different combustion problems and the computational cost embedded in combustion simulations due to model size.

To address the first challenge, flame time is explored as a way to link the flame propagation problem and the auto-ignition problem. This is aimed at facilitating the prediction of laminar burning velocities of fuels from the knowledge of their ignition delay times under given conditions. The dependence of flame time on pressure, temperature, and equivalence ratio is investigated and compared with that of ignition delay time. Laminar burning velocity and ignition delay time simulations are performed for methane at pressures of 1.0-20 bar, equivalence ratios of $0.6-1.6$, and unburnt temperatures of $300-1000 \mathrm{~K}$ using a methane model from the literature. ${ }^{41}$ Laminar burning velocities and thermal diffusivities are used to calculate flame times.

The main findings of the parametric study are that flame time and ignition delay time have similar temperature dependence profiles. Longer ignition delay times are observed compared with flame times at lower pressures. As pressure increases, the gap between both times closes. Parametric exploration results also showed that both flame time and ignition delay time decrease as pressure increases. Ignition delay times are found to have stronger dependence on pressure than flame times. The equivalence ratio dependence of both times is found to be positive, with flame time having a stronger equivalence ratio dependence than ignition delay time. The observed parametric dependencies were quantified using multiple linear regression correlations.

Also, a direct power law correlation between flame time and ignition delay time was developed for methane through linear regression of their natural logarithms, with a positive linear relationship that indicates that slower flame propagation is accompanied by stronger auto-ignition resistance under the same conditions.

To establish comparability of flame time as a combustion property, flame propagation trends of methane are compared with those of propane and ethanol at pressures and equivalence ratios mentioned earlier, using their respective models. ${ }^{42}$ Methane consistently had the longest flame times, which means slower flame propagation. Propane and ethanol generally exhibited similar flame propagation trends, with a possibility for ethanol to have longer flame times than the other two fuels at low pressures and high critical temperatures over $1700 \mathrm{~K}$.

The second challenge is also addressed in this work in a model reduction study that used the SSE method to obtain reduced version of the THF model by Fenard et al. ${ }^{43}$ with THF chosen as the focus of the study as a representative promising second-generation transportation biofuel. Seven reduced versions were developed by applying the SSE approach multiple times over a pressure range of 7.7-20 bar and a temperature range of 750-1200 K. The reduced models are eventually combined into a global skeletal model which is less than half the size of the original model, with only 193 species and 1151 reactions. 
Ignition delay time simulations were performed for THF/air mixtures at stoichiometric conditions and pressures of 6.4 and 9.1 bar using the detailed and the global skeletal models, with predictions of both models compared with shock tube ignition data reported by Fenard et al ${ }^{44}$ under the same conditions. The results show that both models generally over-estimate ignition delay time, with the reduced model showing significant deviation from the detail model as temperature decreases.

To identify the reactions responsible for this behavior, reaction sensitivity analysis was performed to compare the detailed and reduced models at $1000 \mathrm{~K}$ and 9.1 bar. Further reaction sensitivity analysis was performed to compare the findings of the reduced version at temperatures of 700,1000 , and $1300 \mathrm{~K}$. Many pathways are explored from the results, and the main findings of the analyses are that pathways involving that two radicals, tetrahydrofuran-2-yl and tetrahydrofuran-3-yl, are particularly important and reactivity enhancing at intermediate and high temperatures. The observed low priority of pathways leading to tetrahydrofuran-3-yl production at $700 \mathrm{~K}$ is identified as a potential reason for the poor performance of the global skeletal model at low temperatures.

To improve the predictive performance of the developed skeletal model, reaction rate parameters for key reactions are updated with values from the literature ${ }^{45}$ in line with the desired performance, which is increasing the predicted reactivity of the chain reaction leading to shorter ignition delay times, matching experimental data. Reaction rates are increased for four $\mathrm{H}$-abstraction reactions from THF to form the 2-yl and 3-yl radicals, and for a fifth decomposition reaction of hydrogen peroxide to form hydroxyl radical necessary for accelerating the $\mathrm{H}$-abstraction from THF.

Finally, ignition delay times are simulated using the modified skeletal version are compared with the predictions of the unmodified skeletal and detailed models at the same condition. The final modified skeletal model shows excellent agreement with experimental data at most of the conditions. The predictive performance of the final version is overall superior to the both the unmodified reduced model and the original detailed model at the investigated conditions.

The findings of this work highlight similarities of the two separate combustion problems of flame propagation and auto-ignition, and establish the possibility of developing a direct relationship between the timescales for these two problems for any fuel of interest. This direct relationship can provide a basis for future research efforts into designing a machine-learning-based technique for the simultaneous simulation of laminar burning velocity and ignition delay time to eliminate the need for separate simulations for the two combustion events. This would support turbulent combustion and coupled 3D-CFD/ chemical kinetic simulations. A possible expansion of this investigation could involve examining the flame times that correspond with flammability limits, which can provide a sense of the competition for heat transport, kinetic rate, and heat release amount.

With respect to model reduction, further exploratory analysis, such as reaction pathway analysis, can be performed using the reduced and detailed model to better understand the fuel consumption schemes at various temperatures. the SSE method can be modified into an updated version that can use flame time as the target reduction property instead 
of ignition delay time for the development of reduced models that focus on the flame propagation behavior of transportation fuels. Finally, model reduction can be used to develop models that are capable of simulating the auto-ignition behavior of THF blends with gasoline and diesel, as THF can be practically used as an additive to such fuels to improve performance. 


\section{ABBREVIATIONS AND ACRONYMS}

3D-CFD Three-Dimensional Computational Fluid Dynamics

ASE $\quad$ Alternate Species Elimination

$\mathrm{Cl} \quad$ Compression Ignition

DRG Directed Relations Graph

DRGASA Directed Relations Graph and Species Sensitivity Analysis

DRGEP Directed Relations Graph with Error Propagation

DRGX Directed Relations Graph with Expert Knowledge

$\mathrm{HCCl}$ Homogeneous Charge Compression Ignition

RON Research Octane Number

SB-1 California Senate Bill no. 1, Road Repair and Accountability Act

SI Spark Ignition

SSE Stochastic Species Elimination

THF Tetrahydrofuran 


\section{ENDNOTES}

1. Mazen A. Eldeeb, Characterization and Chemical Kinetic Analysis of the Ignition of Representative Conventional and Bio-Derived Fuels (Syracuse, NY: Syracuse University, 2015).

2. Mazen A. Eldeeb et al., "Reduced Chemical Kinetic Models using Alternate and Stochastic Species Elimination" (paper presented at the ASME 2018 Power Conference, Lake Buena Vista, FL, June 24-28, 2018); N. Peters and F. A. Williams, "The Asymptotic Structure of Stoichiometric Methane Air Flames," Combustion and Flame 68 (1987): 185-207; N. Peters et al., "Temperature Cross-Over and Non-Thermal Runaway at TwoStage Ignition of n-Heptane," Combustion and Flame 128 (2002): 38-59; P. Saxena, N. Peters, and F. A. Williams, "An Analytical Approximation for High-Temperature Autoignition Times of Higher Alkanes," Combustion and Flame 149 (2007): 79-90.

3. Yuriy Román-Leshkov et al., "Production of Dimethylfuran for Liquid Fuels from Biomass-Derived Carbohydrates," Nature 447 (2007): 982-985; Xinli Tong, Yang Ma, and Yongdan $\mathrm{Li}$, "Biomass into Chemicals: Conversion of Sugars to Furan Derivatives by Catalytic Processes," Applied Catalysis A: General 385 (2010): 1-13; Chidambaram Mandan and Alexis T. Bell, "A Two-Step Approach for the Catalytic Conversion of Glucose to 2,5-Dimethylfuran in lonic Liquids," Green Chemistry 12 (2010): 1253-1262; Mark Mascal and Edward B. Nikitin, "Direct, High-Yield Conversion of Cellulose into Biofuel," Angewandte Chemie International Edition 120 (2008): 8042-8044.

4. Key World Energy Statistics 2014 (Paris: OECD Publishing, 2014).

5. Mazen A. Eldeeb, Characterization and Chemical Kinetic Analysis of the Ignition of Representative Conventional and Bio-Derived Fuels (Syracuse, NY: Syracuse University, 2015).

6. Ibid.

7. Shaohua Zhong et al., "Combustion and Emissions of 2,5-Dimethylfuran in a DirectInjection Spark-Ignition Engine," Energy \& Fuels 24 (2010): 2891-2899.

8. Yuriy Román-Leshkov et al., "Production of Dimethylfuran for Liquid Fuels from Biomass-Derived Carbohydrates," Nature 447 (2007): 982-985; Xinli Tong, Yang Ma, and Yongdan $\mathrm{Li}$, "Biomass into Chemicals: Conversion of Sugars to Furan Derivatives by Catalytic Processes," Applied Catalysis A: General 385 (2010): 1-13; Chidambaram Mandan and Alexis T. Bell, "A Two-Step Approach for the Catalytic Conversion of Glucose to 2,5-Dimethylfuran in lonic Liquids," Green Chemistry 12 (2010): 1253-1262; Mark Mascal and Edward B. Nikitin, "Direct, High-Yield Conversion of Cellulose into Biofuel," Angewandte Chemie International Edition 120 (2008): 8042-8044.

9. Key World Energy Statistics 2014 (Paris: OECD Publishing, 2014).

10. D. She et al., "Chapter 15 - Front-Tracking Methods," in Handbook of Numerical Analysis, 
vol. 17, 383-402 (Elsevier, 2016).

11. Yakov B. Zeldovich and David A. Frank-Kamenetskii, "The Theory of Thermal Propagation of Flames,” Zhurnal Fizicheskoi Khimii 12 (1938): 100-105.

12. Mazen A. Eldeeb et al., "Reduced Chemical Kinetic Models using Alternate and Stochastic Species Elimination" (paper presented at the ASME 2018 Power Conference, Lake Buena Vista, FL, June 24-28, 2018); N. Peters and F. A. Williams, "The Asymptotic Structure of Stoichiometric Methane Air Flames," Combustion and Flame 68 (1987): 185-207; N. Peters et al., "Temperature Cross-Over and Non-Thermal Runaway at TwoStage Ignition of n-Heptane," Combustion and Flame 128 (2002): 38-59; P. Saxena, N. Peters, and F. A. Williams, "An Analytical Approximation for High-Temperature Autoignition Times of Higher Alkanes," Combustion and Flame 149 (2007): 79-90.

13. Tianfeng Lu and Chung K. Law, "A Directed Relation Graph Method for Mechanism Reduction," Proceedings of the Combustion Institute 30 (2005): 1333-1341.

14. P. Pepiot-Desjardins and H. Pitsch, "An Efficient Error-Propagation-Based Reduction Method for Large Chemical Kinetic Mechanisms," Combustion and Flame 154 (2008): 67-81.

15. X. L. Zheng, T. F. Lu, and C. K. Law, "Experimental Counterflow Ignition Temperatures and Reaction Mechanisms of 1,3-Butadiene," Proceedings of the Combustion Institute 31 (2007): 367-375.

16. Tianfeng Lu et al., "Directed Relation Graph with Expert Knowledge for Skeletal Mechanism Reduction" (paper presented at the 7th US National Combustion Meeting, Atlanta, GA, March 20-23, 2011).

17. Mazen A. Eldeeb et al., "Reduced Chemical Kinetic Models using Alternate and Stochastic Species Elimination" (paper presented at the ASME 2018 Power Conference, Lake Buena Vista, FL, June 24-28, 2018).

18. Ibid.

19. R. J. Kee et al., PREMIX: A FORTRAN Program for Modeling Steady Laminar OneDimensional Premixed Flames (San Diego, CA: Reaction Design, Inc., 1998).

20. A. E. Lutz, R. J. Kee, and J. A. Miller, SENKIN: A Fortran Program for Predicting Homogeneous Gas Phase Chemical Kinetics with Sensitivity Analysis (Livermore, CA: Sandia National Labs, 1988).

21. Andrew E. Lutz et al., EQUIL: A CHEMKIN Implementation of STANJAN for Computing Chemical Equilibria (Livermore, CA: Sandia National Labs, 1998).

22. Eric L. Petersen et al., "Methane/Propane Oxidation at High Pressures: Experimental and Detailed Chemical Kinetic Modeling," Proceedings of the Combustion Institute 31 
(2007): 447-454.

23. Marco Mehl et al., "Kinetic Modeling of Gasoline Surrogate Components and Mixtures under Engine Conditions," Proceedings of the Combustion Institute 33 (2011): 193-200.

24. Eric L. Petersen et al., "Methane/Propane Oxidation at High Pressures: Experimental and Detailed Chemical Kinetic Modeling," Proceedings of the Combustion Institute 31 (2007): 447-454.

25. Nick M. Marinov, "A Detailed Chemical Kinetic Model for High Temperature Ethanol Oxidation," International Journal of Chemical Kinetics 31 (1999): 183-220.

26. Eric L. Petersen et al., "Methane/Propane Oxidation at High Pressures: Experimental and Detailed Chemical Kinetic Modeling," Proceedings of the Combustion Institute 31 (2007): 447-454.

27. Eric L. Petersen et al., "Methane/Propane Oxidation at High Pressures: Experimental and Detailed Chemical Kinetic Modeling," Proceedings of the Combustion Institute 31 (2007): 447-454; Nick M. Marinov, "A Detailed Chemical Kinetic Model for High Temperature Ethanol Oxidation," International Journal of Chemical Kinetics 31 (1999): 183-220.

28. Mazen A. Eldeeb et al., "Reduced Chemical Kinetic Models using Alternate and Stochastic Species Elimination" (paper presented at the ASME 2018 Power Conference, Lake Buena Vista, FL, June 24-28, 2018).

29. Benjamin Akih-Kumgeh, and Jeffrey M. Bergthorson, "Skeletal Chemical Kinetic Mechanisms for Syngas, Methyl Butanoate, n-Heptane, and n-Decane," Energy \& Fuels 27 (2013): 2316-2326.

30. Mazen A. Eldeeb et al., "Reduced Chemical Kinetic Models using Alternate and Stochastic Species Elimination" (paper presented at the ASME 2018 Power Conference, Lake Buena Vista, FL, June 24-28, 2018).

31. Ibid.

32. Yann Fenard et al., "A Model of Tetrahydrofuran Low-Temperature Oxidation Based on Theoretically Calculated Rate Constants," Combustion and Flame 191 (2018): 252-269.

33. Ibid.

34. Ibid.

35. Ibid.

36. Kai Moshammer et al., "An Experimental and Kinetic Modeling Study of 2-Methyltetrahydrofuran Flames," Combustion and Flame 160 (2013): 2729-2743. 
37. Claudia Zavala-Oseguera et al., "OH Radical Gas Phase Reactions with Aliphatic Ethers: A Variational Transition State Theory Study," The Journal of Physical Chemistry A 113 (2009): 13913-13920.

38. D. L. Baulch et al., "Evaluated Kinetic Data for Combustion Modelling," Journal of Physical and Chemical Reference Data 21 (1992): 411-734.

39. Yann Fenard et al., "A Model of Tetrahydrofuran Low-Temperature Oxidation Based on Theoretically Calculated Rate Constants," Combustion and Flame 191 (2018): 252-269.

40. Ibid.

41. Eric L. Petersen et al., "Methane/Propane Oxidation at High Pressures: Experimental and Detailed Chemical Kinetic Modeling," Proceedings of the Combustion Institute 31 (2007): 447-454.

42. Eric L. Petersen et al., "Methane/Propane Oxidation at High Pressures: Experimental and Detailed Chemical Kinetic Modeling," Proceedings of the Combustion Institute 31 (2007): 447-454; Nick M. Marinov, "A Detailed Chemical Kinetic Model for High Temperature Ethanol Oxidation," International Journal of Chemical Kinetics 31 (1999): 183-220.

43. Yann Fenard et al., "A Model of Tetrahydrofuran Low-Temperature Oxidation Based on Theoretically Calculated Rate Constants," Combustion and Flame 191 (2018): 252-269.

44. Ibid.

45. Kai Moshammer et al., "An Experimental and Kinetic Modeling Study of 2-Methyltetrahydrofuran Flames," Combustion and Flame 160 (2013): 2729-2743; Claudia Zavala-Oseguera et al., "OH Radical Gas Phase Reactions with Aliphatic Ethers: A Variational Transition State Theory Study," The Journal of Physical Chemistry A 113 (2009): 13913-13920; D. L. Baulch et al., "Evaluated Kinetic Data for Combustion Modelling," Journal of Physical and Chemical Reference Data 21 (1992): 411-734. 


\section{BIBLIOGRAPHY}

Akih-Kumgeh, Benjamin, and Jeffrey M. Bergthorson. "Skeletal Chemical Kinetic Mechanisms for Syngas, Methyl Butanoate, n-Heptane, and n-Decane." Energy \& Fuels 27 (2013): 2316-2326. https://doi.org/10.1021/ef400121t.

Baulch, D. L., C. J. Cobos, R. A. Cox, C. Esser, P. Frank, Th. Just, J. A. Kerr, et al. "Evaluated Kinetic Data for Combustion Modelling." Journal of Physical and Chemical Reference Data 21 (1992): 411-734. https://doi.org/10.1063/1.555908.

Chidambaram, Mandan, and Alexis T. Bell. "A Two-Step Approach for the Catalytic Conversion of Glucose to 2,5-Dimethylfuran in lonic Liquids." Green Chemistry 12 (2010): 1253-1262. https://doi.org/10.1039/C004343E.

Eldeeb, Mazen A. Characterization and Chemical Kinetic Analysis of the Ignition of Representative Conventional and Bio-Derived Fuels. Syracuse, NY: Syracuse University, 2015. https://surface.syr.edu/etd/385.

Eldeeb, Mazen A., and Benjamin Akih-Kumgeh. "Reduced Chemical Kinetic Models using Alternate and Stochastic Species Elimination." Paper presented at the ASME 2018 Power Conference, Lake Buena Vista, FL, June 24-28, 2018. https://doi. org/10.1115/POWER2018-7242.

Fenard, Yann, Adrià Gil, Guillaume Vanhove, Hans-Heinrich Carstensen, Kevin M. Van Geem, Phillip R. Westmoreland, Olivier Herbinet, and Frédérique Battin-Leclerc. "A Model of Tetrahydrofuran Low-Temperature Oxidation Based on Theoretically Calculated Rate Constants." Combustion and Flame 191 (2018): 252-269. https:// doi.org/10.1016/j.combustflame.2018.01.006.

Kee, R. J., J. F. Grcar, M. D. Smooke, J. A. Miller, and E. Meeks. PREMIX: A FORTRAN Program for Modeling Steady Laminar One-Dimensional Premixed Flames. San Diego, CA: Reaction Design, Inc., 1998.

Key World Energy Statistics 2014. OECD Publishing, 2014. https://doi.org/10.1787/key_ energ_stat-2014-en.

Lu, Tianfeng, and Chung K. Law. "A Directed Relation Graph Method for Mechanism Reduction." Proceedings of the Combustion Institute 30 (2005): 1333-1341. https:// doi.org/10.1016/j.proci.2004.08.145.

Lu, Tianfeng, Max Plomer, Zhaoyu Luo, S. M. Sarathy, W. J. Pitz, Sibendu Som, and Douglas E. Longman. "Directed Relation Graph with Expert Knowledge for Skeletal Mechanism Reduction." Paper presented at the 7th US National Combustion Meeting, Atlanta, GA, March 20-23, 2011.

Lutz, A. E., R. J. Kee, and J. A. Miller. SENKIN: A Fortran Program for Predicting Homogeneous Gas Phase Chemical Kinetics with Sensitivity Analysis. Livermore, 
CA: Sandia National Labs, 1988.

Lutz, Andrew E., Fran M. Rupley, Robert J. Kee, W. C. Reynolds, and Ellen Meeks. EQUIL: A CHEMKIN Implementation of STANJAN for Computing Chemical Equilibria. Livermore, CA: Sandia National Labs, 1998.

Marinov, Nick M. "A Detailed Chemical Kinetic Model for High Temperature Ethanol Oxidation." International Journal of Chemical Kinetics 31 (1999): 183-220. https:// doi.org/10.1002/(SICI)1097-4601(1999)31:3<183::AID-KIN3>3.0.CO;2-X.

Mascal, Mark, and Edward B. Nikitin. "Direct, High-Yield Conversion of Cellulose into Biofuel." Angewandte Chemie International Edition 120 (2008): 8042-8044. https:// doi.org/10.1002/anie.200801594.

Mehl, Marco, William J. Pitz, Charles K. Westbrook, and Henry J. Curran. "Kinetic Modeling of Gasoline Surrogate Components and Mixtures under Engine Conditions." Proceedings of the Combustion Institute 33 (2011): 193-200. https:// doi.org/10.1016/j.proci.2010.05.027.

Moshammer, Kai, Stijn Vranckx, Harish K. Chakravarty, Prajakta Parab, Ravi X. Fernandes, and Katharina Kohse-Höinghaus. "An Experimental and Kinetic Modeling Study of 2-Methyltetrahydrofuran Flames." Combustion and Flame 160 (2013): 2729-2743. https://doi.org/10.1016/j.combustflame.2013.07.006.

Pepiot-Desjardins, P., and H. Pitsch. "An Efficient Error-Propagation-Based Reduction Method for Large Chemical Kinetic Mechanisms." Combustion and Flame 154 (2008): 67-81. https://doi.org/10.1016/j.combustflame.2007.10.020.

Peters, N., and F. A. Williams. "The Asymptotic Structure of Stoichiometric Methane Air Flames." Combustion and Flame 68 (1987): 185-207. https://doi.org/10.1016/00102180(87)90057-5.

Peters, N., G. Paczko, R. Seiser, and K. Seshadri. "Temperature Cross-Over and NonThermal Runaway at Two-Stage Ignition of n-Heptane." Combustion and Flame 128 (2002): 38-59. https://doi.org/10.1016/S0010-2180(01)00331-5.

Petersen, Eric L., Danielle M. Kalitan, Stefanie Simmons, Gilles Bourque, Henry J. Curran, and John M. Simmie. "Methane/Propane Oxidation at High Pressures: Experimental and Detailed Chemical Kinetic Modeling." Proceedings of the Combustion Institute 31 (2007): 447-454. https://doi.org/10.1016/j.proci.2006.08.034.

Román-Leshkov, Yuriy, Christopher J. Barrett, Zhen Y. Liu, and James A. Dumesic. "Production of Dimethylfuran for Liquid Fuels from Biomass-Derived Carbohydrates." Nature 447 (2007): 982-985. https://doi.org/10.1038/nature05923.

Saxena, P., N. Peters, and F. A. Williams. "An Analytical Approximation for HighTemperature Autoignition Times of Higher Alkanes." Combustion and Flame 149 
(2007): 79-90. https://doi.org/10.1016/j.combustflame.2006.12.006.

She, D., R. Kaufman, H. Lim, J. Melvin, A. Hsu, and J. Glimm. "Chapter 15 - Front-Tracking Methods," in Handbook of Numerical Analysis, vol. 17, 383-402. Elsevier, 2016. https://doi.org/10.1016/bs.hna.2016.07.004.

Tong, Xinli, Yang Ma, and Yongdan Li. "Biomass into Chemicals: Conversion of Sugars to Furan Derivatives by Catalytic Processes." Applied Catalysis A: General 385 (2010): 1-13. https://doi.org/10.1016/j.apcata.2010.06.049.

Zavala-Oseguera, Claudia, Juan R. Alvarez-Idaboy, Gabriel Merino, and Annia Galano. "OH Radical Gas Phase Reactions with Aliphatic Ethers: A Variational Transition State Theory Study." The Journal of Physical Chemistry A 113 (2009): 1391313920. https://doi.org/10.1021/jp906144d.

Zeldovich, Yakov B., and David A. Frank-Kamenetskii. "The Theory of Thermal Propagation of Flames." Zhurnal Fizicheskoi Khimii 12 (1938): 100-105.

Zheng, X. L., T. F. Lu, and C. K. Law. "Experimental Counterflow Ignition Temperatures and Reaction Mechanisms of 1,3-Butadiene." Proceedings of the Combustion Institute 31 (2007): 367-375. https://doi.org/10.1016/j.proci.2006.07.182.

Zhong, Shaohua, Ritchie Daniel, Hongming Xu, Jun Zhang, Dale Turner, Miroslaw L. Wyszynski, and Paul Richards. "Combustion and Emissions of 2,5-Dimethylfuran in a Direct-Injection Spark-Ignition Engine." Energy \& Fuels 24 (2010): 2891-2899. https://doi.org/10.1021/ef901575a. 


\section{ABOUT THE AUTHOR}

\section{MAZEN A. ELDEEB, PHD}

Dr. Mazen A. Eldeeb, born in 1987 in Giza, Egypt, is an Assistant Professor of Mechanical Engineering in California State University, Fresno, USA. He received an M.S. degree in mechanical engineering from Cairo University in 2010 and a Ph.D. in mechanical engineering from Syracuse University in 2015. In January 2016 he joined the Department of Mechanical Engineering, California State University, Fresno, as an assistant professor. His research expertise includes experimental characterization of the auto-ignition behavior of pure second-generation biofuels and their blends with gasoline surrogates through shock tube ignition delay time measurements, as well as chemical kinetic modeling and model reduction. His most recent work includes the development of a chemical kinetic model reduction method, Stochastic Species Elimination (SSE), and the preliminary proposal of another model reduction method, Species Propensity (SP). Dr. Eldeeb's past work includes several numerical simulation efforts and reaction pathway explorations of the combustion of various fuels including 2,5-dimethylfuran and its blends with iso-octane, 2-methylfuran, 2-methyltetrahydrofuran, and 2,5-dimethylcyclohexane. His work also includes the development of a novel chemical kinetic model for combustion simulations of 2,5-dimethylfuran blends with a gasoline surrogate from the individual models of both pure fuels, through reduction, rate constant modification, and combination. Recently, Dr. Eldeeb co-authored a major journal review article about the recent developments in the production, combustion characterization, and modeling efforts of furan-based fuels. 


\section{PEER REVIEW}

San José State University, of the California State University system, and the Mineta Transportation Institute (MTI) Board of Trustees have agreed upon a peer review process required for all research published by $\mathrm{MTI}$. The purpose of the review process is to ensure that the results presented are based upon a professionally acceptable research protocol. 


\author{
Founder, Honorable \\ Norman Mineta (Ex-Officio) \\ Secretary (ret.), \\ US Department of Transportation \\ Chair, \\ Abbas Mohaddes (TE 202I) \\ President \& COO \\ Econolite Group Inc. \\ Vice Chair, \\ Will Kempton (TE 2022) \\ Retired \\ Executive Director, \\ Karen Philbrick, PhD \\ (Ex-Officio) \\ Mineta Transportation Institute \\ San José State University \\ Richard Anderson \\ (Ex-Officio) \\ President \& CEO \\ Amtrak \\ David Castagnetti (TE 202 I) \\ Co-Founder \\ Mehlman Castagnetti \\ Rosen \& Thomas \\ Maria Cino (TE 202 I) \\ Vice President \\ America \& U.S. Government \\ Relations Hewlett-Packard Enterprise
}

\author{
Grace Crunican* \\ (TE 2022) \\ Retired
}

Donna DeMartino (TE 202I)

General Manager \& CEO

San Joaquin Regional Transit District

Nuria Fernandez* (TE 2020)

General Manager \& CEO

Santa Clara Valley

Transportation Authority (VTA)

John Flaherty (TE 2020)

Senior Fellow

Silicon Valley American

Leadership Form

Rose Guilbault (TE 2020)

Board Member

Peninsula Corridor

Joint Powers Board

Ian Jefferies (Ex-Officio)

President \& CEO

Association of American Railroads

Diane Woodend Jones

(TE 2022)

Principal \& Chair of Board

Lea + Elliott, Inc.
Therese McMillan

(TE 2022)

Executive Director

Metropolitan Transportation

Commission (MTC)

Bradley Mims (TE 2020)

President \& CEO

Conference of Minority

Transportation Officials (COMTO)

Jeff Morales (TE 2022)

Managing Principal

InfraStrategies, LLC

Dan Moshavi, PhD

(Ex-Officio)

Dean, Lucas College and

Graduate School of Business

San José State University

Takayoshi Oshima (TE 202 I)

Chairman \& CEO

Allied Telesis, Inc.

Toks Omishakin

(Ex-Officio)

Director

California Department of

Transportation (Caltrans)
Paul Skoutelas (Ex-Officio)

President \& CEO

American Public Transportation

Association (APTA)

Dan Smith (TE 2020)

President

Capstone Financial Group, Inc.

Beverley Swaim-Staley (TE 2022)

President

Union Station Redevelopment

Corporation

\section{Jim Tymon (Ex-Officio)}

Executive Director

American Association of

State Highway and Transportation

Officials (AASHTO)

\section{Larry Willis (Ex-Officio)}

President

Transportation Trades

Dept., AFL-CIO

$(\mathrm{TE})=$ Term Expiration

* = Past Chair, Board of Trustees

\section{Directors}

Karen Philbrick, Ph.D.

Executive Director

Hilary Nixon, Ph.D.

Deputy Executive Director

\section{Asha Weinstein Agrawal,}

\section{Ph.D.}

Education Director

National Transportation Finance

Center Director

\section{Brian Michael Jenkins}

National Transportation Security

Center Director

\title{
Research Associates Policy Oversight Committee
}

Jan Botha, Ph.D.

Civil \& Environmental Engineering

San José State University

Katherine Kao Cushing,

\section{Ph.D.}

Enviromental Science

San José State University

Dave Czerwinski, Ph.D. Marketing and Decision Science San José State University
Frances Edwards,

Ph.D.

Political Science

San José State University

Taeho Park, Ph.D.

Organization and Management

San José State University

\section{Christa Bailey}

Martin Luther King, Jr. Library

San José State University

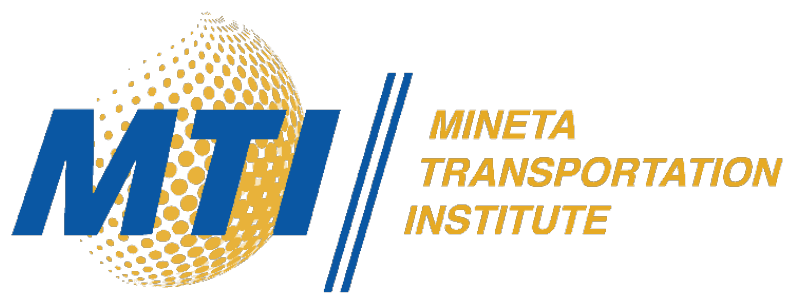

